\title{
The World of Fifty (Interoperable) Facebooks
}

\author{
Przemysław Pałka*
}

This Article envisions a "world of fifty facebooks," where numerous companies would offer interoperable services, similar to the one currently provided by Facebook Inc. As is the case with telephones, where customers of AT\&T can call and text those of T-Mobile or Verizon, users of A-Book should be able to find, communicate with, and see the content of customers of B-Book, C-Book, etc. Facebook Inc. should be required to allow potential competitors to become interoperable with its platform and to grant them access to its network. Today, Facebook Inc. uses its artificially created monopolistic position to impose excessive costs and unnecessary harms on consumers and society.

This Article presents a new theory of the "price" that Facebook Inc. charges for its services, going beyond the conventional wisdom that users pay for access with their "personal data and attention." It argues that Facebook Inc. imposes on its users: (i) cognitive harms (emotional manipulation, risk of psychological and mental health problems); (ii) behavioral harms (unwanted purchases, wasted time, risk of addiction); and (iii) privacy/security harms (risk of having amassed personal data stolen by hackers). The company also (iv) freerides on users' creative content and labor. Each of these harms constitutes a higher "price" or lower quality than could be available in a competitive market. Importantly, these costs do not result from the necessary features of " $a$ facebook" but rather from Facebook Inc.'s data-collection-heavy,

\footnotetext{
${ }^{*}$ Assistant Professor at the Future Law Lab, Faculty of Law and Administration of the Jagiellonian University in Krakow, Poland; Affiliated Fellow at the Information Society Project at Yale. For the inspiration and support I want to thank Fiona Scott Morton, Theodore Nierenberg Professor of Economics at the Yale University School of Management and the founding director of Thurman Arnold Project at Yale. Moreover, I want to thank Jack Balkin, Anna Buchta, Christoph Busch, Bartosz Brożek, Lingxi Chenyang, Ignacio Cofone, Aggarwal Dhruv, Kasper Drażewski, Austin Frerick, Ewa Górska, Nikolas Guggenberger, Jaap Hage, Luke Herrine, Agnieszka Jabłonowska, Mitchell Jonhston, Dawid Juszka, Thomas Kadri, Bonnie Kaplan, Michael Karanicolas, Bartłomiej Kucharzyk, Ewa Laskowska-Litak, Kamil Mamak, Daniel Markovits, Hans-W. Micklitz, Rafael Nunes, Art Pericles, Malwina Popiołek, Jonathan Sarnoff, Giovanni Sartor, Christina Spiesel, Ramesh Subramanian, Kazimierz Ujazdowski, Laurin Weissinger and Bohdan Widła for their helpful comments and suggestions at various stages of this project.
} 
targeted-advertising-driven business model. Less harmful models, however, are available.

The Article surveys possible legal strategies for achieving and sustaining "the world of fifty facebooks." As the debates about regulation of large platforms continue in the US and the EU, this Article serves as a reminder that, as a society, we face a choice. We might accept the central role that platforms like Facebook Inc. currently play in our socioeconomic lives and focus solely on taming the most abusive behaviors they engage in. Alternatively, we might embrace the fact that there is nothing natural nor necessary about this position and concentrate on restructuring the online power relationships. Doing so requires imagination and political will, and this Article aims at fostering both.

I. INTRODUCTION

II. WHAT IS "A FACEBOOK"?

A. A Multifunctional Tool and the Network of Users................ 1203

1. A "Phonebook" and the Network Effects ........................ 1204

2. Messaging and Social Coordination ................................ 1206

3. Content Production and Consumption ............................. 1207

4. The Network and the ID System......................................... 1208

B. The World of Fifty Facebooks -A First Glance..................... 1209

III. THE COSTS OF USING FACEBOOK TODAY .................................................. 1212

A. Data-Fueled, Ad- and Engagement-Driven Business Model 1213

B. Harms to Consumers: Higher "Prices" and Lower Quality 1216

1. Cognitive Costs: Emotional Manipulation, Mental Health Problems 1216

2. Behavioral Costs: Behavioral Manipulation, Addiction, Wasted Time 1220

3. Privacy (as Security) Costs: Opportunity Makes the Thief 1224

4. Free Riding on Users' Intellectual Property and Labor 1225

IV. TOWARD THE WORLD OF FIFTY FACEBOOKS ........................................... 1228

A. Interoperability ................................................................... 1228

B. Regulation for, and of, Competition......................................... 1231

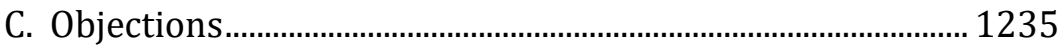

D. Scaling Up-Toward Anti-Platform Law? ............................ 1238

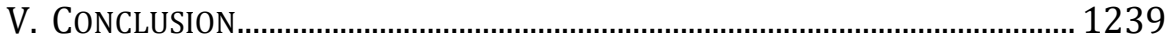




\section{INTRODUCTION}

Imagine a world where the telephone was invented ten years ago and ever since has been offered by one company only, Telephone Inc. Imagine that Telephone Inc. insists that it is technologically impossible for other providers to be interoperable with its product. If you use Telephone Inc., you can only call and receive calls from other Telephone Inc. customers. Even when Smartphone Inc. creates a similar and complementary service, you cannot use it to call people who are Telephone Inc. customers. As a result, even though other companies would like to enter the market and compete by offering lower prices and higher quality, network effects prevent them from doing so. Everyone is already "on Telephone." Subsequently, the monopolist can impose contract conditions that consumers would not have otherwise accepted, such as listening to all of your phone calls and inserting ads in the middle of conversations.

You might think this thought experiment is strange; phones of various providers can obviously be interoperable with one another. But ask yourself, would this be evident to an inhabitant of a world where the telephone has always been provided by just one company? Inhabitants of that world still need to realize this otherwise simple fact.

We are the inhabitants of that world, though it is Facebook Inc., not Telephone Inc., that we falsely believe to be a "natural" monopolist.

Facebook Inc. is currently the monopolist in the market for facebooks, the new universal way to communicate and coordinate social life. ${ }^{1}$ It excludes competitors from offering consumers similar services by artificially creating access barriers to the network of the platform's users. $^{2}$ Given the network effects-"everyone" already "being on

1 Throughout the Article, the word "Facebook" is used in three different ways: (1) "Facebook Inc." refers to the company; (2) "Facebook" refers to the platform (the product) offered by Facebook Inc.; (3) and "a facebook" refers to the kind of communication tool that Facebook is an example of.

2 Moreover, Facebook Inc. has proactively engaged in various strategies aimed at removing emerging competitors in their nascent forms in order to preserve its dominance. See Tim Wu, The Curse of Bigness: Antitrust in the New Gilded Age 119-26 (2018). According to Jon Sarlin, Facebook Inc. uses a three-prong strategy of "buy, deny and apply," where it either purchases early-stage potential competitions, including Instagram in 2012 and WhatsApp in 2014; denies competitors access to its data or APIs (as was the case with Vine); or copies functionalities developed by other companies (as was the case with Snapchat, and now with Facebook Dating). The "deny" strategy especially exemplifies how Facebook Inc. purposely limits its technical interoperability to limit competition. See Jon Sarlin, This is How Facebook Kills its Competition, CNN BusinEss (Mar. 21, 2019) https://www.cnn.com/videos/business/2019/03/21/this-ishow-facebook-kills-its-competition.cnn-business/video/playlists/business-facebook. These activities are at the core of the most recent lawsuit that the Federal Trade Commission [hereinafter "the FTC"] has filed against Facebook Inc., together with 48 
Facebook" - potential competitors cannot fairly compete on quality and price. $^{3}$

There is nothing "natural" or "necessary," however, about Facebook Inc.'s monopoly over the network of people using the service of "a facebook." ${ }^{4}$ Facebook is not like railways, or bridges, or the electric grid. ${ }^{5}$ Technologically speaking, just like with the telephone, facebooks provided by different companies could be interoperable with one another. ${ }^{6}$ It is a question of how we want to structure the world we live in; a question of imagination and political will. You could be using ABook, I could be using B-Book, and our friend could be using C-Book, and still, we should be able to add each other as friends, communicate and coordinate social life through the same medium offered by different providers. We would all have access to the same "online space," just provided by many companies, offering varying business conditions. This world is technologically possible. Why is it normatively desirable?

Attorneys General. See Cecilia Kang \& Mike Isaac, U.S. and States Say Facebook Illegally Crushed Competition, N.Y. TimEs, Dec. 9, 2020, https://www.nytimes.com/2020/12/09/ technology/facebook-antitrust-monopoly.html; Press Release, Fed. Trade Comm'n, FTC Sues Facebook for Illegal Monopolization (Dec. 9, 2020), https://www.ftc.gov/newsevents/press-releases/2020/12/ftc-sues-facebook-illegal-monopolization [hereinafter "the FTC's Facebook lawsuit press release"].

3 See Thomas E. Kadri, Digital Gatekeepers, 99 TEXAS L. REv. __ (forthcoming 2021) (manuscript at 34), https://papers.ssrn.com/sol3/papers.cfm?abstract_id=3665040 (arguing that “[d]ue to the network effects that underlie many platforms' success, people are loath to experiment with new players unless enough of their friends do too. Interoperability is one way to counteract these high switching costs, and protecting adversarial interoperability ensures that the existing platforms don't retain a veto power over innovation that threatens their market dominance").

4 For an argument that Facebook is a "natural monopoly," see, e.g., Dipayan Ghosh, Don't Break Up Facebook-Treat It Like a Utility, Harv. Bus. Rev. (May 30, 2019), https://hbr.org/2019/05/dont-break-up-facebook-treat-it-like-a-utility ("I contend that Facebook and firms like it have become natural monopolies that necessitate a novel, stringent set of regulations to obstruct their capitalistic overreaches and protect the public against ingrained economic exploitation.").

5 Even if, for the adjudication purposes, it might sometimes be useful to act as if it was similar to railroads or other infrastructure. For an example of such a case, see Nikolas Guggenberger, Essential Platforms, 24 STAN. TECH. L. REv. __ (forthcoming 2021) (manuscript at 3), https://papers.ssrn.com/sol3/papers.cfm?abstract_id=3703361 (arguing that the doctrine of essential facilities should be applied to temper platforms' dominant position, as "[w] hat the railroads were to the early twentieth century, digital platforms have become to the early twenty-first century"). Guggenberger is correct as a matter of description, but unlike railroads for trains, platforms do not have to be allencompassing vehicles for online interaction.

6 See infra Section IV.A. For an explanation of how opening the APIs could lead to much higher interoperability between the online platforms, see Katarzyna Szymielewicz, A New Deal for Data, STARTUP (Nov.14, 2019), https://medium.com/swlh/ a-new-deal-for-data-1c6d7c850e25. 
As a monopolist, Facebook Inc. can impose various costs on consumers, costs that consumers would refuse to accept in a competitive market. Those go beyond the conventional wisdom according to which "users pay for Facebook with data and attention" 7 and include (i) cognitive harms, ${ }^{8}$ (ii) behavioral harms, ${ }^{9}$ (iii) privacy/security harms, ${ }^{10}$ and (iv) freeriding on users' creative content and labor. ${ }^{11}$ One might treat these costs as a higher "price" that users pay or lower quality of the service that consumers receive. ${ }^{12}$ But there is no necessary connection between these costs and the features of the service Facebook Inc. provides to consumers.

On the contrary, these costs are a consequence of a toxic business model-based on never-ending data collection and targeted advertising-which Facebook Inc. can rely on, given its monopolistic position. ${ }^{13}$ This business model incentivizes Facebook Inc. to "addict" users to the platform and have them engage as much as possible, even if this means that more "negative" content is shown to them. ${ }^{14}$ Other business models are possible, however, including subscription fees, or revenue from non-data-collection-driven advertising, or a model where

7 See, e.g., Ghosh, supra note 4 ("The currency extracted from individuals in the consumer internet context is typically not money, but a novel, complex combination of the individual's personal data and attention.").

8 See infra Section III.B.1; see also Jaron Lanier, TEn Arguments for Deleting Your Social Media Accounts Right Now 81-92 (2018); Przemysław Pałka, Private Law and Cognitive Science, in LAW AND Mind (Bartosz Brozek \& Jaap Hage eds., forthcoming 2021).

9 See infra Section III.B.2; see also Julie E. Cohen, BetweEn Truth and Power: The Legal Constructions of Informational Capitalism 83-98 (2019); Shoshana Zuboff, The Age of Surveillance Capitalism: The Fight for a Human Future at the New Frontier of Power 74-96 (2019); Ido Kilovaty, Legally Cognizable Manipulation, 34 BERKELEY TECH. L.J. 449, 461-73 (2019).

10 See infra Section III.B.3. See generally Ido Kilovaty, Privatized Cybersecurity Law, 11 U.C. IRVINE L. REV. (forthcoming 2021).

11 See infra Section III.B.4; see also ERIC A. Posner \& E. Glen Weyl, RAdicAl Markets 205-23 (2018).

12 For a general overview of harmful effects of the online platforms operating based on their current business models, see James Niels Rosenquist \& Fiona M. Scott Morton, The Disutility of Exploitative Technology: Implications for Regulation and Antitrust (Working Paper presented at the "Big Tech and Antitrust Conference" at Yale Law School in New Haven CT, on Oct. 3-4, 2020; manuscript with the author); see also STIGLER CTR. Comm. for the Study of Dig. Platforms, Market Structure and Antitrust Subcommittee REPORT 23-138 (2019), https://www.chicagobooth.edu/research/stigler/news-andmedia/committee-on-digital-platforms-final-report [hereinafter "THE STIGLER REPORT"].

13 See infra Section III.A.

14 See Jack BALKIN, Fixing Social Media's Grand BARgain 4 (2018), https://www.hoover.org/sites/default/files/research/docs/balkin_webreadypdf.pdf ("The more digital companies know about people's emotional vulnerabilities and predispositions, the more easily they can structure individual end-user experience to addict end users to the site."); LANIER, supra note 8; Rosenquist \& Scott Morton, supra note 12 . 
users are compensated for their creativity and labor. ${ }^{15}$ The price of using "a facebook" could be much lower. ${ }^{16}$

Hence, I argue that Facebook Inc. should be required to give potential competitors access to its platform and network, allowing other companies to offer similar and complementary services which are interoperable with the Facebook service and network. I envision a "world of fifty facebooks," with many businesses competing on price, quality, and innovation. These companies could offer people novel contractual conditions, better corresponding to what consumers actually prefer. For example, A-Book could offer no data collection and no ads, but a subscription fee. B-Book could offer could offer an adbased model with less data collection and with fact-checking as a part of the service. C-Book could compensate its users for their time, labor, and content, etc. Moreover, complementary services (add-ons) could emerge in addition to these full-fledged substitutes, ranging from companies curating and moderating content to enhancing the experience in any other way. Such competition would allow consumers to better express their preferences, minimize the consumer surplus extraction by the monopolist, and lead to higher consumer benefits and more efficient allocation of social resources. But it will only become possible once the network of facebooks users is not intrinsically linked to one service, as it is today.

Competition in the market for facebooks is necessary, but not sufficient, to tackle all the harms and costs of informational capitalism. ${ }^{17}$ The newly created market will need to be regulated, both to ensure the interoperability of the services (technical standards) ${ }^{18}$ and to minimize

15 See infra Section III.A. For arguments supporting compensation not just for content and labor but for all the harms stemming from using social media (claiming that the surplus is much lower than we tend to assume) see generally Hunt Allcott, Luca Braghieri, Sarah Eichmeyer \& Matthew Gentzkow, The Welfare Effects of Social Media, 110 AM. ECon. REv. 629 (2019).

16 "Price" both as in "the price for a cup of coffee is $\$ 3$ " and "a knee injury is the price you pay for jogging in the wrong shoes."

17 For the definition of the term, see CoHEN, supra note 9, at 5-6 ("[T] he alignment of capitalism as a mode of production with informationalism as a mode of development. Capitalism 'is oriented toward profit-maximizing, that is, toward increasing the amount of surplus appropriated by capital on the basis of the private control over the means of production and circulation,' while informationalism 'is oriented ... toward the accumulation of knowledge and towards higher levels of complexity in information processing.' In a regime of informational capitalism, market actors use knowledge, culture, and networked information technologies as means of extracting and appropriating surplus value, including consumer surplus.").

18 As is the case with telephones. See Ian Walden, Access and Interconnection, in Telecommunications LAW AND Regulation (Ian Walden ed. 2018); see also infra Section IV.B. 
some externalities, such as certain types of discrimination ${ }^{19}$ and manipulation. ${ }^{20}$ Nevertheless, the regulation of service providers' conduct is one of the possible modes of governance; we should not discount other options, including market forces. ${ }^{21}$ And, for these forces to operate, competition is necessary. As of today, Facebook Inc. has none. It is up to us, as a society, to decide whether we want to accept the central role of the large platforms and only regulate them at the margins, or whether we will challenge their position. At least regarding Facebook Inc., I argue we should do the latter.

There are many ways to transition from the world we live in now to the "world of fifty facebooks." They include, among others, enacting new regulation and enforcing existing antitrust laws. It is not my ambition in this Article to outline these strategies in detail. I do not engage with questions of how a particular policy reform should be conducted (institutionally, or what should be the exact content of rules), or how the antitrust case should be argued. Each of these questions would need a paper of its own. I look at the problem from the bird's-eye policy perspective and from a conceptual standpoint. This means that for a reader deeply immersed in technical debates in telecommunications law, ${ }^{22}$ utilities regulation, ${ }^{23}$ or antitrust law, ${ }^{24}$ my usage of terms like "monopolist," "product market" or "interoperability" 25 might seem rather general. This is because, rather than arguing for a particular interpretation of existing laws, or a specific phrasing of the provisions to be enacted, I want to make a normative

19 For a discussion of race- and gender-based discrimination in data-driven ad delivery, see Latanya Sweeney, Discrimination in Online Ad Delivery, 1301 ARXIV 6822 (2013), https://arxiv.org/abs/1301.6822; see also Muhammad Ali et al., Discrimination through Optimization: How Facebook's Ad Delivery Can Lead to Skewed Outcomes, 1904 ARXIV 02095 (2019), https://arxiv.org/abs/1904.02095.

20 See Eliza Mik, The Erosion of Autonomy in Online Consumer Transactions, 8 L. InNOVATION \& TECH. 1, 1-2 (2016). See generally Kilovaty, supra note 9.

21 For the canonical discussion the interrelationship between law and regulation, design and markets see generally LAWRENCE LESSIG, CodE AND OTHER LAWS OF CyBERSPACE (1999).

22 See Walden, supra note 18.

23 For an analysis of Facebook's (and other tech companies) behavior from the perspective of utilities regulation, see generally K. Sabeel Rahman, The New Utilities: Private Power, Social Infrastructure, and the Revival of the Public Utility Concept, 39 CARDozo L. REv. 1621 (2018).

24 For an example of how an antitrust case against Facebook could be argued in the United States, see Dina Srinivasan, The Antitrust Case Against Facebook: A Monopolist's Journey Towards Pervasive Surveillance in Spite of Consumers' Preference for Privacy, 16 BERKELEY BuS. L.J. 39 (2019). For an argument for changing the way we understand the logic of antitrust law in the technology sphere, though on the case study of Amazon, not Facebook, see Lina M. Khan, Amazon's Antitrust Paradox, 126 YALE L.J. 710 (2017).

25 See infra Section IV.A. 
claim regarding the aims that the law should pursue. I sketch the goal and justify it. My ambition is to imagine the world of fifty facebooks, convince the reader we should aim at it, and sketch the possible pathways without providing an itinerary.

At the time of this writing, two important developments have just occurred. First, on December 9, 2020, the FTC, together with the Attorneys General of forty-six states, the District of Columbia, and Guam, filed a lawsuit against Facebook Inc. ${ }^{26}$ The lawsuit petitions "for a permanent injunction and other equitable relief against Defendant Facebook, Inc., ... to undo and prevent its anticompetitive conduct and unfair methods of competition in or affecting commerce in violation of Section 5 [of the FTC Act]."27 In particular, the FTC seeks to break up Facebook horizontally ("divestiture of assets, divestiture or reconstruction of businesses (including, but not limited to, Instagram and/or WhatsApp")). ${ }^{28}$ Moreover, it intends to significantly limit future mergers and acquisitions, ${ }^{29}$ as well as to halt anticompetitive behavior in vertical relations. ${ }^{30}$

It is hard to overstate the importance of this lawsuit. Of course, it will take time, and without a doubt, Facebook Inc. will fight back hard. But the process is already in motion. Importantly, even though the FTC did not ask the court to require Facebook Inc.'s horizontal interoperability (though, arguably, it does seek to increase vertical interoperability), we should remember that the case can come to an end in various ways. It might end up with a judgment, but it might just as well (and probably will) be resolved through a settlement. There, the parties can agree to anything, including horizontal interoperability. I hope that this Article serves as a source for inspiration for why the FTC should pursue this goal and provide additional ammunition for those seeking to explain why exactly Facebook Inc.'s artificial monopolization of access to the network of users comes with a significant cost to society and consumers. Hopefully, a similar suit will follow across the Atlantic, in the European Union. In the end, Facebook Inc.'s conduct is in breach

26 See Complaint, Fed. Trade Comm'n v. Facebook, Inc., No. 1:20-cv-03590 (D.D.C. Jan. 13, 2021), https://www.ftc.gov/system/files/documents/cases/051_2021.01.21_ revised_partially_redacted_complaint.pdf [hereinafter "The FTC's Facebook Lawsuit"] (Public redacted version of document filed under seal); see also Cecilia Kang \& Mike Isaac, U.S. and States Say Facebook Illegally Crushed Competition, N.Y. TIMES, Dec. 9, 2020, https://www.nytimes.com/2020/12/09/technology/facebook-antitrustmonopoly.html.

27 The FTC's Facebook Lawsuit, supra note 26 at 1.

28 Id. at 51.

29 Id.

30 Id. at 52 (noting "that Facebook is permanently enjoined from imposing anticompetitive conditions on access to APIs and data"). 
of a fundamental principle of the liberal democratic political economy, i.e., opposition to the unchecked private power of a monopolist. ${ }^{31}$ This principle, on the small " $c$ " constitutional level, is very similar both in the US and the EU, even if the details of the laws concretizing this principle are different in both jurisdictions. ${ }^{32}$

Second, on December 15, 2020, the European Commission released drafts of the long-awaited Digital Services Act (DSA) ${ }^{33}$ and Digital Market Act (DMA). ${ }^{34}$ The former instrument seeks to "set out uniform rules for a safe, predictable and trusted online environment, where fundamental rights enshrined in the Charter are effectively protected,"35 whereas the latter lays down "rules ensuring contestable and fair markets in the digital sector across the Union where gatekeepers are present."36 Given that these laws, when enacted, will apply to the American-based companies directing their services at European Union residents, one should keep them in mind when seeking ways to create the world of fifty facebooks. The current versions hint at interoperability several times, especially regarding ad-repositories, ${ }^{37}$ various information sharing systems, ${ }^{38}$ and non-discrimination in access to the APIs. ${ }^{39}$ This is, by far, not enough; however, the legislative process has just begun, and the text can still be changed. The enactment of the General Data Protection Regulation ${ }^{40}$ in 2016, which, despite

31 See $\mathrm{Wu}$, supra note 2, at 76-77.

32 But, despite some significant differences between the particular solutions and the currently predominant normative theories in both jurisdictions, the internal logic of the antitrust laws in the US and the EU are quite similar. See Guggenberger, supra note 5, at 47 (arguing that, at least genealogically, the European and the American antitrust law are much closer aligned that one would nowadays assume). For a comprehensive comparison of these two systems, see RichaRd S. MARKOVITS, ECONOMICS AND THE INTERPRETATION AND APPLICATION OF U.S. AND E.U. ANTITRUST LAWS (2014).

33 See European Commission Proposal for a Regulation of the European Parliament and of the Council on a Single Market For Digital Services (Digital Services Act) and amending Directive 2000/31/EC, Brussels, Eur. PARL. Doc. (COM(2020) 825), https://eur-lex.europa.eu/legal-content/EN/TXT/HTML/?uri=CELEX:52020PC0825\& from=en [hereinafter "the DSA"].

34 See European Commission Proposal for a Regulation of the European Parliament and of the Council on contestable and fair markets in the digital sector (Digital Markets Act), Eur. PARL. Doc. (COM (2020) 842), https://eur-lex.europa.eu/legal-content/EN/ TXT/HTML/?uri=CELEX:52020PC0842\&from=en [hereinafter "the DMA"].

35 See the DSA, supra note 33, art. 1.2.b.

36 See the DMA, supra note 34, art.1.1.

37 See the DSA, supra note 33, art. 34.1.e.

38 Id. art. 67.

39 Id. art. 6.1.c, 6.1.f.

40 Regulation (EU) 2016/679, of the European Parliament and the Council of 27 April 2016 on the protection of natural persons with regard to the processing of 
being heavily lobbied, ended up establishing quite consumer-friendly obligations on companies, is one reason to believe that the Europeans will succeed in laying down strict rules governing companies like Facebook Inc. But-and this is of utmost importance-it is not enough to "tame" large online platforms' behavior. The very structure of online power can be decentralized and democratized, and I hope that this Article will serve as an encouragement to do so for the European legislators.

This Article consists of three parts. Part II explains exactly what service Facebook Inc provides from the consumers' point of view and why it constitutes its own product market, where the platform and the network are intrinsically connected. It also imagines what a competitive market in facebooks could look like. Part III demonstrates why the current business model of Facebook Inc. is not necessary, surveys the types of harms it imposes on consumers, and demonstrates how those harms could be avoided in a competitive market. Part IV sketches some ideas about the legal strategy for transitioning from the status quo to the "world of fifty facebooks," including a more general analysis of the concept of interoperability, the role of regulation as both a facilitator of competition, and as a way to combat certain abusive practices across the board.

\section{WHAT IS “A FACEBOOK”?}

In this Part, I argue that "a facebook" is a new, universal tool for social communication, intrinsically connected to the network of people using it. Facebook Inc. created this tool and is currently the monopolist in the market for facebooks. I explain why, instead of thinking about Facebook Inc. as competing in the market for "social media," we should treat its service and network as a separate type of product. I analyze what the characteristics of this product are. Finally, I provide a first sketch of the world where several companies, fully interoperable with one another, could be offering the same type of service, or some complementary add-ons to it. 


\section{A. A Multifunctional Tool and the Network of Users}

From the consumers' (users') perspective, ${ }^{41}$ a facebook is essentially seven things, analytically capable of being studied separately, but phenomenologically necessarily interrelated:

1. A Search Engine for People/Uniform Identifier System, where one can "find" a person using the search function and "friend" or "follow" them. In this sense, a facebook is a "phonebook," all-encompassing and perpetually up to date;

2. A Direct Messaging System, where the messenger tool allows people to call or send messages to each other;

3. A Coordination Tool, where users can coordinate logistics of common projects and social life, through functionalities like Events, Groups, or Marketplace;

4. A Blogging/Vlogging Service, where each user's Timeline is their own personal site, supported by an interface allowing the user to upload content and enabling others to engage with it by "reacting" with emojis, commenting, or sharing-a tool for content production;

5. A Content Aggregator, where each user sees a personalized Newsfeed and does not have to "visit" blogs she is interested in individually but can simply rely on the provider's algorithm to display the most "relevant" content-a tool for convenient content consumption;

6. A Tool for Accessing the Network of People simultaneously using the same service;

7. An ID system, allowing users to "log into" other services using their Facebook account.

These seven functionalities, taken together, characterize the product offered by Facebook Inc. in the year 2021 and, subsequently, the product market in which Facebook Inc. operates. Other "social media companies"-like Twitter, LinkedIn, TikTok, etc.-offer different types of products. These products cannot be substitutes, both because they lack certain functionalities that render a facebook the universal

41 For purposes of this Article's argument, I am not looking at the services that Facebook provides for advertisers and its role in the ads market. The reason is that, as I show, ads are not a conceptually necessary part of the Facebook environment; the company's business model could be different when monetization of the consumer product is concerned, and it is the consumer product that I want to focus on. For analysis of Facebook's role in the ads market, from the competition policy perspective, see British Competition and Mkts. Auth., Online Platforms and Digital Advertising: Market STUDY InTERIM REPORT (2020), https://www.gov.uk/cma-cases/online-platforms-anddigital-advertising-market-study. 
tool of communication and because their networks are not interoperable.

What makes Facebook so appealing to users, such that despite numerous scandals concerning privacy, ${ }^{42}$ experimenting on users without their consent, 43 alleged negative consequences for mental health, ${ }^{44}$ and a dubious role in the political process, ${ }^{45}$ Facebook's user base is growing, ${ }^{46}$ generating more and more profits for the company? ${ }^{47}$ This, in one sense, is an empirical question, requiring rigorous qualitative and quantitative studies, which I would be more than happy to see conducted. It is also a conceptual question, however, and below I offer a theory explaining what makes Facebook not only a product market of its own but also such a desirable product that people are willing to pay a much higher price for it than necessary.

\section{A "Phonebook" and the Network Effects}

Let us start with the first functionality listed above, the one that gave Facebook its name-a facebook, a search engine for people and a tool for staying connected. Many American colleges and professional schools print such booklets for their students, faculty, and staff, facilitating intra-institutional communication. After a couple of years, however, these booklets are no longer useful for communication (they might be useful for archival purposes, or as souvenirs). But what if these booklets somehow updated themselves all the time? You pull out a catalog of your classmates from ten years ago, see their current pictures, phone numbers, occupation, and emails? That would be useful, wouldn't it?

42 For an overview of privacy scandals that Facebook has been involved in, see James Sanders \& Dan Patterson, Facebook Data Privacy Scandal: A Cheat Sheet, TechRepublic (July 24, 2019), https://www.techrepublic.com/article/facebook-data-privacyscandal-a-cheat-sheet.

43 See Kashmir Hill, Facebook Manipulated 689,003 Users' Emotions for Science, ForBES (June 28, 2014, 2:00 PM), https://www.forbes.com/sites/kashmirhill/2014/06/ 28/facebook-manipulated-689003-users-emotions-for-science; see also Kilovaty, supra note 9 , at 473 .

44 See Ravi Chandra, Is Facebook Destroying Society and Your Mental Health?, PsYCH. Today (Jan. 29, 2018) https://www.psychologytoday.com/us/blog/the-pacific-heart/ 201801/is-facebook-destroying-society-and-your-mental-health.

45 See Nicholas Confessore, Cambridge Analytica and Facebook: The Scandal and the Fallout So Far, N.Y. Times (Apr. 4, 2018), https://www.nytimes.com/2018/04/04/us/ politics/cambridge-analytica-scandal-fallout.html.

46 See infra Section III.A.

47 See infra Section III.A. 
Try to imagine all the people that you know, whom you have met at some point: your friends and teachers from high school, former colleagues, distant relatives, people you met at a conference, etc. That is a large group. You do not have most of their phone numbers or email addresses. There is a significant group of people that you "know," you "met," but whom you cannot reach.

Facebook solves this problem. Especially for the generations that en masse signed up for it-definitely the millennial generation $(82 \%$ of American millennials are Facebook users) ${ }^{48}$-but also for $30 \%$ of the entire Earth's population, ${ }^{49}$ there is a very high chance that people can stay in touch using the platform. If you add someone as a friend in college, they will "remain your friend" a decade later. If you meet someone at a party, an easy way to stay in touch is to become friends on Facebook. You can do it on your computer or using your smartphone. It is convenient, fast, and reliable. Additionally, even if you did not add someone as a friend on Facebook at the time when you met, you can still find them there later. The "search" function, combined with the company's policy requiring people to use their real names ${ }^{50}$ and the functionality displaying "common friends" with other people, is a powerful tool for "rediscovering" and "reconnecting with" people you once met.

In this sense, Facebook Inc.'s product is an ever-updated college facebook, or, even better, a universal phonebook. A phonebook where, instead of phone numbers, you get to "friend" someone and message them on Facebook. And where the absolute monopolist is Facebook Inc. For, to be able to rely on this "phonebook" - as there are no "phone numbers," only the ability to connect within the specific service-you need to be a user of Facebook.

48 Out of 71 million millennials in the United States, 58.3 million are Facebook users. This amounts to 82 percent. See J. Clement, Number of Facebook Users By Age in the U.S. 2018, STATISTA (Aug. 14, 2019), https://www.statista.com/statistics/398136/usfacebook-user-age-groups; Millennials, WIKIPEDIA, https://en.wikipedia.org/wiki/ Millennials (last visited Dec. 31, 2020).

49 Facebook reported its monthly user base reached 2.498 billion in 2019. See Facebook Investor Relations, Facebook Quarterly Earnings Slides, at 3, https://s21.q4cdn.com/399680738/files/doc_financials/2019/q4/Q4-2019-EarningsPresentation-_final.pdf [hereinafter "Facebook 2019 report"]. At the time of this Article's writing, Earths population equals 7.83 billion, see World Population, WORLDOMETER, https://www.worldometers.info/world-population (last visited Dec. 31, 2020). Both numbers are growing.

50 See Terms of Service, FАСЕВОок, https://www.facebook.com/terms.php (last visited Dec. 31, 2020) ("When people stand behind their opinions and actions, our community is safer and more accountable. For this reason, you must ... [u]se the same name that you use in everyday life.") [hereinafter "Facebook Terms"]. 


\section{Messaging and Social Coordination}

Facebook is not just a "phonebook," it is also a tool for communication and social coordination. You can text, send files or images, call, or video call all your "friends." It is a modern phone. Of course, other tools allow you to do the same-email, texting, or Skype. But to communicate with people using those tools, you need to know their number, email address, or Skype ID. A facebook is both a way to find someone and to contact them. Besides, there are tools other than direct messaging and calls, making communication and coordination even more accessible.

Facebook also allows you to create "events" and invite people to your public lecture, a birthday party, or a movie marathon. These events can be private or public. You can use them to coordinate with your close friends, with people you somehow know, and even to promote open to the public activities you organize.

Then, there are "groups:" a group for legal scholars, for local volunteers, for your sports team, for philosophy fans, etc. The groups are the next incarnation of "online forums." To give an anecdotal example, one of my younger cousins, currently in middle school, created a Facebook account because the entirety of the communication among her peers, from social life to homework self-help, was being coordinated via a Facebook group. As anecdotal as this example might be, it indicates a wider trend-to be "included" becomes largely synonymous with having to use the services of Facebook Inc. Some people might have the luxury to opt out; many others, however, have little choice other than to start a Facebook account.

Finally, various other functionalities for coordination-like Facebook "marketplace" (competition to eBay), "dating" (competition to Tinder or Bumble), or "jobs" (competition to LinkedIn), and others (definitely in the pipeline)-make access to the network even more profitable as different kinds of coordination are enabled. But, as of today, the only way to get access is to use the services of Facebook Inc.

All this taken together-the ability to find people, to stay in touch, and to communicate with them through various types of tools dedicated to the particular needs of humans-makes Facebook so appealing. And we have not even gotten to perhaps the most visible functionality of Facebook-that of content creation and consumption. 


\section{Content Production and Consumption}

You learn a lot of information on Facebook, from the fact that your primary school friend got married and had a baby, to the fact that a new funny cat video is available, to social and political news. Over half of Americans read their news on social media (here this category also includes other sites). ${ }^{51}$ Facebook is a way to consume content, from gossip, over entertainment, to information.

At the same time, if you choose to, you can keep the world informed about what you are up to in the same way. You got a new job-change your "about" section on Facebook. Your relationship status changedindicate that on Facebook. ${ }^{52}$ You took a nice photo, read an interesting article, want to spread knowledge about a local initiative-share it on Facebook. It is a tool for informing your peers about your life, thoughts, and ideas.

Moreover, especially during the COVID-19 pandemic, the ability to "go live" on Facebook-produce or consume streaming video-has become incredibly useful to many people and organizations. Large swaths of our lives, including lectures and classes, religious services and prayers, motivational talks, and workouts, moved online, many of them to Facebook. Of course, other providers-YouTube and Zoom among them-made going live possible. If you are organizing an online lecture, however, Facebook presents many advantages, not least the fact that you can invite literally every one of your Facebook friends, which could be close to everyone you know. If your class, church, or club already communicates via a Facebook group, this will be a natural platform to do streaming.

Finally, Facebook enables users to be creative and produce content, as well as to be passive or active content consumers. If your friend shares something you find outrageous, you can indicate that with an "angry" emoji or write a comment. If you prefer, however, you can refrain from reacting, and just scroll further. In this sense, Facebook is a TV and a newspaper, where everyone can be the producer, and everyone can re-print/re-broadcast (by linking or sharing) the content of others. And it is up to you to choose who will see what. Content may be public or private, but you always have the option to allow your

51 See Peter Suciu, More Americans Are Getting Their News From Social Media, FoRBES (Oct. 11, 2019), https://www.forbes.com/sites/petersuciu/2019/10/11/moreamericans-are-getting-their-news-from-social-media.

52 This phenomenon is so widespread that numerous memes emerged, where the pun usually is the celebrant saying, "I now pronounce you husband and wife, you may now change your relationship status." Everything Funny, PINTEREST, https://www.pinterest.com/pin/25825397835850492/. 
"friends" to see your content, just as they have the option to allow you to see theirs.

\section{The Network and the ID System}

From a user's perspective, what matters is that all these functionalities are available at the same time, within the same service, internally interoperable. Each functionality is useful and worth something. But the total utility a Facebook user derives from the platform is not just the sum of these utilities. It is also the usefulness of being able to rely on various functionalities when communicating with various people interchangeably. If you meet someone at a work conference and "friend" them on Facebook to stay in touch, akin to asking for their phone number, you also benefit from seeing the content they share, the comments they make on your posts, or the groups they might invite you to in the future.

Other social media might serve some of the needs that Facebook does. Twitter is a great platform to share and consume content, but not for finding your primary school friends. It does not allow you to call your contacts, or to create events or groups. LinkedIn might be a good professional tool for authenticating your $\mathrm{CV}$, building a professional network, and helping you find some people you met, but it will not be a source of funny content or a way to organize a birthday party for your child. Facebook is the new universal communication tool, allowing one to do all these things in one place.

Moreover, Facebook accounts-given the company's requirement to use one's actual name - can often be used as a reliable way to identify people online. For this reason, numerous other services-from Spotify to Tinder to a host of others-allow you to log in to their services using your Facebook account. Once you do so, it is harder to quit. Not impossible, but harder.

In the context of all these considerations, we can begin to grasp the power of the network effects that benefit Facebook Inc. Facebook Inc. is not just a neat product or a robust network of people but instead a robust network of people using a neat product at the same time.

There is no technical reason, however, why this medium of communication, and access to the global network of people, needs to be provided by one operator only. 53 Facebook can be interoperable with other platforms serving exactly the same needs, or providing subsidiary services-it is possible to open up the network to competitors' access. ${ }^{54}$

53 See Szymielewicz, supra note 6.

54 Id. 
The reason we do not live in this world is a business reason-Facebook Inc., unless forced by the law to open up to competition, has no interest in sharing its full dominance in the market for facebook(s) with other actors. Hence, to change this state of affairs, the law needs to step in. Governing bodies must undertake new regulations, antitrust cases, or both, requiring the company to open up. The success of these interventions, at least on the policy level, depends on demonstrating why Facebook Inc.'s monopoly position is harmful to consumers, why it potentially already constitutes an abuse of dominance, and why the law should intervene to remedy the situation in which we currently find ourselves.

To offer an answer to these questions-i.e., survey what the costs of using Facebook currently are-let us take a brief look at the possible future I have in mind. What could "the world of fifty (interoperable) facebooks" look like?

\section{B. The World of Fifty Facebooks-A First Glance}

In the world I envision, many corporations would compete in the facebooks market. They would offer services consisting of the functionalities described above: allowing users to connect with other people; message them; coordinate conduct; and create, share, and consume content. Most importantly, they would all allow the consumers to connect with the entire network of the facebooks' users, just like people using different mobile phone providers can call and text one another. They would share the common identification system for users, just like the telephone companies all "recognize" each other's phone numbers, and would not discriminate against users of other platforms when access to their users is concerned.

In this world, you could be a user of A-Book (showing no ads but charging a subscription fee), I could be a user of B-Book (showing ads, but based on my chosen preferences, not based on data collected without my understanding), and still, we would be able to find each other in the search bar, add each other as friends, send messages to each other, invite each other to events or groups, see each other's content, and have our content seen by one another. The user experience, though not necessary, could remain similar across platforms. For example, we could still see the aggregated content in the newsfeed, events and groups in a side tab, and a search bar on top. Or it could be different, whatever the innovators propose and consumers choose. Maybe some users prefer a social media provider with no newsfeed, but something else. The difference would be such that each of us will be able to choose the facebook provider whose services we want to receive, freely migrate 
between providers, and benefit from the competition between the providers. What matters is that consumers would be able to not only choose the functionalities they like but also the contract terms they prefer. What alternative business models are possible?

First, consider a subscription fee. A new facebook provider could offer access to the platform and the network in exchange for monthly payments while refraining from collecting more data than necessary to provide the service, remaining ad-free, and giving users greater control over the newsfeed algorithm. In the "tech sector," we already pay to stream music and videos, for access to newspapers, etc. Why wouldn't some people choose to pay for the fundamental medium of communication, if that payment allowed them to avoid data collection and the behavioral and cognitive costs?

How much would it cost? Of course, this would depend. We can make some (very) rough estimates, however, based on publicly available data. Facebook Inc.'s revenue for the fourth quarter of 2019 in the US and Canada was $\$ 10.24$ billion, out of which $\$ 10.02$ billion (98 percent) came from advertising, 55 with 248 million monthly active users. $^{56}$ Hence, on average, a user in the US and Canada generated revenue equal to $\$ 13.70$ a month. During the same period, the company's global revenue was $\$ 21.08$ billion, with 2,498 billion monthly active users. ${ }^{57}$ This amounts to a monthly average revenue of $\$ 2.84$ per user worldwide. 58

For comparison, a monthly Netflix subscription in the US ranges between $\$ 8.99$ and $\$ 17.99,{ }^{5}$ while Spotify costs $\$ 9.99,60$ and Amazon Prime \$12.99.61 A \$12 subscription fee for a facebook does not seem in any way excessive. Especially if, in exchange, data collection ceases, and the risks of cognitive and behavioral harms decline.

55 See Facebook Investor Relations, Facebook Q4 2019 Results, at 9-10, https://s21.q4cdn.com/399680738/files/doc_financials/2019/q4/Q4-2019-EarningsPresentation-_final.pdf.

56 Id. at 3.

57 Id. at 3-4, 8.

58 Id. In this sense, Northern American users are unsurprisingly "subsidizing" users in less developed countries. The types of harms suffered by these users are similar, however, and potentially more serious, given less accessible mental healthcare and/or less strict data (privacy) laws.

59 See Choose The Plan That's Right For You, NETFLIX, https://www.netflix.com/ signup/planform (last visited Jan. 11, 2021).

60 See Pick Your Premium, SPотіFY, https://www.spotify.com/us/premium (last visited Jan. 11, 2021).

61 See Try Prime, AMAZon, https://www.amazon.com/amazonprime (last visited Jan. 11, 2021). 
Further, unlike Netflix and Spotify, Facebook Inc. does not pay licenses to copyright holders and/or content producers. Unlike Amazon Prime, it does not pay for the large logistical operation of two-day delivery. Its costs are lower. Of course, Facebook Inc. needs to finance its operations (data storage, software development, secure servers, etc.), but at least a part of Facebook Inc.'s current business costs are the costs of the data-heavy, ad-based business model. In a world of no ads and no data analytics, the cost of running the business would go down as well.

Another possible business model could rely on less targeted advertising. Instead of having data collected about them, users could be required to indicate a certain number of categories of products they are interested in or provide certain "static" types of information, like hobbies, age, type of job, etc. The service provider could then display "generic" advertisements aimed at a particular kind of audience. Such a model would not automatically remove some types of costs, like the risk of behavioral manipulation, but would decrease other costs, like the risk of addiction or a data breach. Whether such a model would generate enough revenue to keep the service "free" is an empirical question that nobody can answer, precisely because of Facebook Inc.'s current dominance. Nevertheless, in the world of fifty facebooks, this could be tested.

Yet another option is to leave things roughly as they are but compensate users for their labor, content, and activity. For the majority of users, this would not be a particularly significant payment, but for others hoping to attract the attention of millions, the payments could be significant. Nevertheless, even the small amounts could constitute the consumer surplus; there is no reason why the monopolist should be in a position to keep all of it.

Moreover, once companies operating facebooks are legally required to allow other companies access to their network and platforms, products serving as add-ons (complementary services) and not merely substitutes, could emerge. For example, YourFeed Inc. could offer to curate content displayed on your facebook's newsfeed. A-Book could offer their own proprietary algorithm to determine what content you see but also enable other companies to perform that function for the user-and it would be up to the user to choose. Or GroupHost Inc. could offer a service hosting interest groups (just like Facebook Groups now), recommend those that match your interests, or think of new ways to facilitate communication, and consumers would be able to find those groups in the search bar of the facebook they use. Or HappyBday Inc. could offer various ways to send greetings to your friends celebrating 
birthdays about which you learn from your facebook as well. Possibilities are infinite. Of course, each of these services would need to make money somehow, through ads, charging a subscription fee, or in yet another way.

Why would we want to do that, one may ask, if Facebook is free? Why bother with new regulations? Can antitrust really be helpful here, since even if we accept Facebook Inc. has the dominant position in the facebook(s) market, it is hard to demonstrate any abuse if the price is zero? The answer is Facebook is not free, the price is not zero, and Facebook Inc.'s conduct harms competition and consumers by providing lower quality than possible, charging higher prices than optimal, and stifling innovation.

Let us see how.

\section{The COSTS OF USING FACEBOOK TODAY}

This Part analyzes why exactly using Facebook Inc.'s services is not "free." I go beyond the conventional wisdom that users pay for access with their "data and attention," 62 and outline exactly what economic and non-economic harms users incur. These harms include (i) cognitive harms (emotional manipulation and risks for mental health), (ii) behavioral harms (unwanted purchases, wasted time, risk of addiction), (iii) privacy/security harms (risk of a data breach), and (iv) Facebook Inc.'s freeriding on users' creative content and labor. I demonstrate how many of these harms are contingent upon Facebook Inc.'s business model, and how many of these harms could be avoided in a world where users can actually choose the conditions of access and service. Two caveats are due.

First, I conceptualize the "harms" inflicted by Facebook Inc. as cost/price/quality to enable discussion internal to individualist, market-logic-oriented discussions in economic law. This, I want to be clear, is not to disregard other normative theories of why what Facebook Inc. does is "bad." Many other accounts, principally opposed to the neoliberal market logic, are possible. Such accounts would focus on the protection of "dignity" or "autonomy" of persons, 63 or even refute the individualistic approaches to data harms altogether, focusing rather

62 See Ghosh, supra note 4.

63 This way of approaching the problem is typical for European law and technology scholars. See, e.g., Mireille Hildebrandt, Smart Technologies and the End(s) of LaW (2015); Roger Brownsword, Rights, Regulation and the Technological Revolution (2008). 
on the relational and societal impacts. ${ }^{64}$ I welcome these accounts. My aim, however, is to show that even within the market logic, the monopolistic behavior of Facebook Inc. needs to be evaluated negatively.

Second, I firmly believe that not all "data-related" harms should be conceptualized as "privacy" harms. ${ }^{65}$ There is a tendency to treat all instances of data collection, analysis, sharing, and usage as "privacy" problems. This tendency is understandable given that, historically, "privacy" has been the category employed to consider limiting who can do what with whose information, and this approach has clarified and enriched how we view some negative aspects of the data economy. ${ }^{66}$ But treating all data-related harms as problems of "privacy" prevents us from seeing other harms stemming from data management. In many ways, Facebook Inc. does respect and protect users' privacy. We have significant control over who can see what information we share, and we are not afraid that Mark Zuckerberg will call our friends and tell them embarrassing facts about us. Facebook Inc. does not use data to "disclose" secrets of our lives. It uses data to squeeze money out of us. And this begs for a different conceptual framework.

\section{A. Data-Fueled, Ad- and Engagement-Driven Business Model}

One needs to distinguish the analysis of Facebook as a service, looking at what it does, and Facebook Inc.'s business model, looking at how the company makes money. The two are not necessarily linked but the user experience is largely shaped by the latter. To understand the costs to consumers and how they could be avoided, one must closely scrutinize incentives inherent to the current business model and consequences for the corporation's behavior.

Conventional wisdom is that Facebook Inc., albeit "free" in monetary terms, offers its service to consumers in exchange for their "data" and/or "attention." 67 This appears to be a two-party, mutual

64 See Salome Viljoen, Democratic Data: A Relational Theory for Data Governance (2020) (unpublished manuscript), https://papers.ssrn.com/sol3/papers.cfm?abstract_ id=3727562.

65 See Przemysław Pałka, Data Management Law for the 2020s: The Lost Origins and the New Needs, 68 BufF. L. Rev. 559, 627-30 (2020).

66 Id. For some marvelous takes on the social role of privacy and theories of privacy harms, see Lisa M. Austin, Privacy and Private Law: The Dilemma of Justification, 55 McGill L.J. 165 (2010); Julie E. Cohen, What Privacy Is For, 126 HARV. L. Rev. 1904 (2013); Ignacio N. Cofone \& Adriana Z. Robertson, Privacy Harms, 69 HASTings L.J. 1039 (2018); Daniel J. Solove, I've Got Nothing to Hide and Other Misunderstandings of Privacy, 44 SAN DiEGo L. REv. 745 (2007).

67 See Ghosh, supra note 4. 
transaction: Facebook Inc. provides an interactive facebook, while you provide your data and your attention. This statement is misleading, even if partly true. Indeed, Facebook Inc. collects information about its users, and, as we have heard many times by now, "data is the new oil."68 But Facebook Inc. cannot pay taxes on users' data nor treat data as currency when paying employee salaries or shareholder dividends. Facebook Inc. needs money-real money.

Mark Zuckerberg himself offered another take on Facebook Inc.'s business model in a now-famous exchange with Senator Orrin Hatch during the April 2018 Congressional hearings. ${ }^{69}$ When Hatch asked, "[H]ow do you sustain a business model in which users don't pay for your service?" Zuckerberg answered, "Senator, we run ads."70 Zuckerberg's answer, though it caused laughter in the chamber and sparked mockery online, was not entirely accurate. Many outlets run ads, from radio to newspapers to TV channels, and yet none of these outlets have been accused of spying on customers, ${ }^{71}$ experimenting on them, ${ }^{72}$ or enabling Russia to meddle in the American election..$^{73}$ Only a few of them are "free," and none of them generate such high profits as Facebook Inc. does. There must be something more.

In reality, Facebook Inc.'s business model is to run data-driven, personalized, targeted advertisements in an environment designed to have users spend a significant amount of time engaging with content on the platform. ${ }^{74}$ The reason Facebook Inc. collects data about individual users is not only to learn about their preferences and simply "match" ads with these preferences but also to infer new knowledge about other users, constantly refine the effectiveness of its ad-delivery system, and ensure that users spend as much time as possible on the platform. ${ }^{75}$ Facebook Inc.'s revenue increases with the number of advertisements it can display, which, in turn, is a function of how many users Facebook has, how much time they spend using the platform, and how effective advertisers believe the ads to be.

68 For the history of the slogan and its critique, see James Bridle, Opinion: Data Isn't The New Oil-It's The New Nuclear Power, TED (July 17, 2018), https://ideas.ted.com/ opinion-data-isnt-the-new-oil-its-the-new-nuclear-power.

69 See Transcript of Mark Zuckerberg's Senate Hearing, WASH. Post (Apr. 10, 2018), https://www.washingtonpost.com/news/the-switch/wp/2018/04/10/transcript-ofmark-zuckerbergs-senate-hearing.

70 Id.

71 See Zuboff, supra note 9.

72 See infra Section III.B.1.

73 The direct cause of these hearings was the Cambridge Analytica scandal. See Confessore, supra note 45.

74 See BALKIN, supra note 14.

75 See LANIER, supra note 8. 
In this business model, Facebook Inc. has an incentive to:

1. encourage users to spend as much time as possible on the platform;

2. have users share as much content and engage with as much content (including ads) as possible;

3. collect and analyze the data about the engagement, also in a "provoked" manner, when Facebook Inc. not only observes how you react to a certain type of content but also periodically tests its hypotheses.

This "engaged time spent on the platform" constitutes both an opportunity to sell more ads and an opportunity to constantly refine the ad-delivery system by testing new techniques, generating new knowledge about how to increase users' time on Facebook and their chances of clicking on the ads. Finally, it is in Facebook Inc.'s direct interest to demonstrate that ads run on its platform lead to actual purchases, even if these purchases are less reflective of actual consumer preferences and more reflective of the effectiveness of "targeted sales" techniques. ${ }^{76}$

A more accurate restatement of the transactional relationship between Facebook Inc. and its individual users would be the following: We provide you "an interactive facebook," with all its functionalities and access to an immense network of people you can communicate with. In exchange, you agree that (i) we will collect information about all your connections and your behavior on our platform and beyond; ${ }^{77}$ (ii) we will use this information to tailor your experience in such a way that you spend as much time on our platform as possible so that we can collect even more information; and (iii) we will show you advertisements, based on data we collected about you and data we inferred about you from the large databases we have, in such a way that you click on as many as possible, and buy as much as possible.

In this sense, logging into the facebook provided by Facebook Inc. is a little bit like walking into a casino. Of course, you will derive some utility from being here, but you know that the casino is smarter than you and the environment is designed to squeeze money out of you, but you still accept that, with all the consequences for which we are not liable. ${ }^{78}$

\footnotetext{
76 See infra Section III.B.2.

77 See Geoffrey A. Fowler, Facebook Will Now Show You Exactly How It Stalks YouEven When You're Not Using Facebook, WASH. Post (Jan. 28, 2020), https://www.washingtonpost.com/technology/2020/01/28/off-facebook-activitypage.

78 See Facebook Terms, FAСЕВоок, https://www.facebook.com/terms.php (especially Section 4.3, "Additional Provisions: Limits on Liability").
} 
Note how this business model is neither a necessary nor "natural" way of financing the service Facebook Inc. provides. It could give users the same functionalities and access to the same network without collecting so much data about them, without showing them ads, and without trying to convince them to spend even more time on the platform. It could simply charge a subscription fee.

For the sake of the argument, let us imagine that a competitorGreenbook Inc.-emerges and promises to collect no more data about users than strictly necessary to provide the service, show no ads, and instead charges users $\$ 12$ a month. Let us imagine that Facebook Inc. is legally required to allow Greenbook to be interoperable with its network and platform, suddenly creating a choice for consumers. They can obtain access to the same, huge network of people, and many neat functionalities, either for $\$ 12$ a month or for "free" with Facebook Inc. Why would anyone choose to switch? The simplest answer would be that it is rational if the benefits exceed the costs.

\section{B. Harms to Consumers: Higher "Prices" and Lower Quality}

1. Cognitive Costs: Emotional Manipulation, Mental Health Problems

Facebook Inc. inflicts cognitive costs on consumers by intentionally and unintentionally making them experience thoughts and emotions that, given a choice, they would prefer not to experience, or for which, in a competitive market, they would prefer to be compensated. These cognitive costs include, among others, emotional manipulation and mental health problems.

As far back as 2012, Facebook Inc. conducted an experiment on 689,003 of its users aimed at testing whether the platform can influence what emotions its users experience based on what content they are being displayed. ${ }^{79}$ The authors of the study, published in 2014, wrote that,

[e]motional states can be transferred to others via emotional contagion, leading people to experience the same emotions without their awareness.... In an experiment with people who use Facebook, we test whether emotional contagion occurs outside of in-person interaction between individuals by reducing the amount of emotional content in the News

79 Adam D. I. Kramer, Jamie E. Guillory \& Jeffrey T. Hancock, Experimental Evidence of Massive-Scale Emotional Contagion Through Social Networks, 111 PRocEEDINGS OF THE NAT' L ACAD. OF SCI. 8788, 8788 (July 22, 2014), https://www.pnas.org/content/111/24/ 8788; see also Kilovaty, supra note 9. 
Feed. When positive expressions were reduced, people produced fewer positive posts and more negative posts; when negative expressions were reduced, the opposite pattern occurred. These results indicate that emotions expressed by others on Facebook influence our own emotions, constituting experimental evidence for massive-scale contagion via social networks. ${ }^{80}$

This experiment has been widely criticized and led to media uproar, ${ }^{81}$ in part because Facebook Inc. did not receive the participants' informed consent, nor did it compensate the users. It was one of many similar experiments that Facebook Inc. conducted. ${ }^{82}$ The company later issued an apology, noting, however, that it had a right to behave in this way under its Terms of Service. ${ }^{83}$ In the aftermath of the scandal, Facebook Inc. stopped publishing scientific papers about its experiments; however, no evidence suggests that it stopped conducting such tests. In other words, Facebook Inc. may still be conducting experiments, believing it has the right to do so, but simply not informing the public.

Why would Facebook Inc. conduct such experiments? In addition to researchers' curiosity, there are good business reasons (contingent upon the business model) to be able to manipulate users' emotions.

First, research suggests that the emotions we experience influence our engagement with content, including with ads. In particular, positive emotions lead to people sharing content more often, while negative emotions increase clicks on pages, including ads. ${ }^{84}$ Put simply, the ability to influence users' emotions increases advertising campaigns' effectiveness. Second, the ability to influence users' emotions leads to more data being generated. Jaron Lanier suggests that negative

80 See Kramer, supra note 79, at 8788.

81 See Vindu Goel, Facebook Tinkers With Users' Emotions in News Feed Experiment, Stirring Outcry, N.Y. Times (June 29, 2014), https://www.nytimes.com/2014/06/30/ technology/facebook-tinkers-with-users-emotions-in-news-feed-experiment-stirringoutcry.html.

82 For an overview of all experiments that Facebook conducted on its users that observers were able to document, see Anya Zhukova, Facebook's Fascinating (and Disturbing) History of Secret Experiments, MAKE USE OF (Apr. 27, 2017), https://www.makeuseof.com/tag/facebook-secret-experiments/.

83 See Samuel Gibbs, Facebook Apologises for Psychological Experiments on Users, GuARDIAN, (July 2, 2014), https://www.theguardian.com/technology/2014/jul/02/ facebook-apologises-psychological-experiments-on-users.

84 See Dan Baum, How Emotion Influences Buying Behavior (And Marketers Can Use it), IMPACT (Apr. 13, 2017), https://www.impactplus.com/blog/emotion-influencebuying-behavior; Peter Noel Murray, How Emotions Influence What We Buy, Psych. TodaY (Feb. 26, 2013), https://www.psychologytoday.com/us/blog/inside-the-consumermind/201302/how-emotions-influence-what-we-buy. 
emotions like fear, anger, and envy lead people to become more engaged and react more to content than do positive emotions. 85 Third, this ability can help Facebook Inc. influence users to spend more time on the platform. ${ }^{86}$

Facebook Inc. is in the business of marketing knowledge creation. Facebook Inc. collects raw data, creates cognitive knowledge about how people behave, and monopolizes the use of that knowledge in sales. This is how the company makes money.

Note that if Facebook Inc. was a research institution, it would need not only to abide by codes of ethics and obtain users' informed consent for participation in such experiments ${ }^{87}$ but it would also need-most probably - to compensate the users for the time spent and/or negative emotional impact. Hence, hidden experiments on users' emotions and behavior, conducted without compensation, constitute a higher price than consumers could otherwise be paying.

Moreover, several studies suggest that Facebook and other social media platforms increase the chance of experiencing psychological problems, including depression ${ }^{88}$ and feelings of loneliness. ${ }^{89}$ Arguably, instilling such emotions in users need not be Facebook Inc.'s goal, but it does constitute an unintended and tolerated negative consequence that, in a competitive market, could be avoided. Of course, some level of negative psychological impacts-stemming from looking at "cool lives" of our "friends," or looking at one's phone instead of interacting with others in person, etc.-will always occur. ${ }^{90}$ To minimize such an effect, however, a company should be able to tell the user, "Hey, I think you spent enough time here today." And Facebook Inc. will never do that. Hence, the negative emotions experienced by Facebook's users as a side

85 See LANIER, supra note 8.

86 Id.

87 Any researcher conducting experiments on human subjects knows that getting an ethical committee approval ex ante is a necessary condition for such an experiment to be justifiable. For a discussion of various novel difficulties regarding informed consent in the current age, see contributions in BEYOND Autonomy: Limits AND ALTERnATIVES TO InfoRmed Consent in Research Ethics AND LAW (David G. Kirchhoffer \& Bernadette J. Richards eds., 2019).

88 See Denis Campbell, Depression in Girls Linked to Higher Use of Social Media, GUARDIAN (Jan. 3, 2019), https://www.theguardian.com/society/2019/jan/04/ depression-in-girls-linked-to-higher-use-of-social-media.

89 See generally Melissa G. Hunt et al., No More FOMO: Limiting Social Media Decreases Loneliness and Depression, 37 J. Soc. CuINIC. Psych. 751 (2018).

90 Helmut Appel, Alexander L. Gerlach \& Jan Crusius, The Interplay Between Facebook Use, Social Comparison, Envy, and Depression, 9 CuRrent OPInIon In Psych. 44, 44-49 (2016). 
effect of using the platform constitute a lower quality of the product that could occur in a competitive market.

Now let us imagine how in a competitive market, where Greenbook Inc. offers the same service that is financed through a subscription fee, the cognitive costs could be avoided. As Greenbook Inc.'s revenue would not depend on targeted ads, the incentives to collect (and generate) data about the users' behavior (including tracking them on other sites) would significantly decrease. There would be no reason for Greenbook Inc. to want to manipulate users' emotions, as it would not benefit from learning how they respond to content when they are angry, happy, or depressed. Greenbook Inc. just wants users to keep paying the subscription fee. As many users will want to retain access to the network of other facebooks' customers, Greenbook Inc. will want to ensure that its customers enjoy their service more than that of the competitors. And in light of growing psychological research about the negative consequences of Facebook Inc.'s business model, Greenbook Inc. could try to convince people that its platform is just much healthier for users' minds. It could, for example, give users an opportunity to design their own algorithms for content curation, or offer various modes like "happy mode" or "relax mode," where the newsfeeds would be filled with content instilling positive emotional reactions. Of course, to be able to do so, it would need some feedback as well. The fundamental difference, however, would be the character of the relationship between the provider and the users. Instead of spying on the latter and treating them as guinea pigs, the former would see them as partners. It could collect feedback in a manner designed to ensure anonymity, just like social scientists do. It could be transparent about the ways it filters content. But most importantly, Greenbook Inc. would have an incentive to truly care about its users' psychological wellbeing, as opposed to increasing their "engagement" at a high cognitive cost.

Would all the psychological harms go away? Of course not. There is no way to make sure that your friend does not share a photo that triggers you or makes you unhappy. There will always be situations when the user gets slightly depressed by looking at photos of her friends relaxing on the beach, or playing with their babies, or doing anything else. Some of the psychological harms that users of facebooks suffer stem not from the service's design but from a much broader set of problems present in our societies. But the fundamental difference between Facebook Inc. and Greenbook Inc. is that the latter would not only not benefit from you experiencing the negative emotions but would also have an incentive to make sure that if you do not want to experience them you have a way to do so. For example, you indicate on Greenbook, 
"No vacations/baby/career photos today." You could tell Greenbook, "No political content today." Such an approach would engrain in the company's business model a partnership between users and the company, wherein the company has an interest in users' psychological wellbeing. ${ }^{91}$

As of today, Facebook Inc. does not see you this way. This is because being able to influence the way you feel (even if this means negative emotions) helps Facebook Inc. influence the way you behave.

2. Behavioral Costs: Behavioral Manipulation, Addiction, Wasted Time

Facebook Inc. inflicts behavioral costs on its consumers by intentionally and unintentionally making them engage in conduct that, given a choice, they would prefer not to engage in or for which, in a competitive market, they would prefer to be compensated. This includes both on-the-spot purchases caused by ads displayed by Facebook Inc. and spending more time on the platform than users would prefer to, including the possibility of addiction..$^{92}$ Note that these costs are related to and, to a certain extent, depend upon the cognitive costs.

As Facebook Inc.'s profits stem from advertising, it has an indirect incentive to prove that advertising through its channels increases sales. A good faith way of proving this increase is documenting actual sales increases (as opposed to lying about it to the advertisers, which is a separate problem). One might wonder, however, if there is anything inherently wrong with increasing sales through effective advertising.

From the microeconomic perspective, advertisements could be deemed to serve three functions. They (i) spread information; (ii) shape preferences; and (iii) influence on-the-spot behavior. Within the classical law and economics imaginary, the first function is good, ${ }^{93}$ the second is arguably neutral, ${ }^{94}$ and the third is potentially negative; for example, if it makes consumers act against their actual preferences. ${ }^{95}$ How is this last instance possible? Consider an example.

91 For a detailed explanation of why this is a paramount societal problem, and survey of ways achieve it, see Thomas E. Kadri, Networks of Empathy, 2020 UTAH L. REv. 1075, 1083-93 (2020).

92 See Anindita Chakraborty, Facebook Addiction: An Emerging Problem, 11 AM. J. PSYCHIATRY 7 (2016).

93 The "perfect information" assumption is a part of the "perfectly competitive markets" view. See Rory Van Loo, Digital Market Perfection, 117 MicH. L. REv. 815, 830-33 (2019).

94 Assuming that others can compete, NGOs can run their own campaigns, journalists can investigate, etc.

95 See Mik, supra note 20, at 14-16. 
Imagine you are driving home after a long day and plan to cook fish with vegetables for dinner, as you have these ingredients in the fridge, and your doctor told you to cut out meat and salt. Suddenly the music on the radio stops and commercials begin. You hear some fun music, people laughing, a sound of a fizzy drink being poured onto ice cubes, and then a pleasant voice says "Had a rough day? Need to regenerate? Why wait? Come to B-Burger for our dinner special of a quarter pounder with cheese, large fries, and a coke for \$9.99." "Ok, that's a good deal," you think, and suddenly you can feel the emptiness of your stomach and saliva gathering in your mouth. You take a turn and, ten minutes later, find yourself munching through a burger. The burger is amazing for a while until you get back home and look at those poor veggies, which will go bad any day now, remembering that you really wanted to get healthier and realizing you did something you did not want to do. You got tricked by an ad. ${ }^{96}$ of course, one can argue that what you actually did was maximize your short-term preference, no matter how short it was. But such an account has perfect explanatory power with zero predictive power-taken to the extreme, such a view would force us to believe that every choice a consumer makes, no matter how quickly she comes to regret it, is aligned with her preferences. We need to be able to distinguish between people's stable preferences and their wants triggered in moments of vulnerability created by hunger, exhaustion, or stress. ${ }^{97}$

This phenomenon has been theorized by economists under various labels, including "hyperbolic discounting" and "time inconsistency."98 Ramsi Woodcock argues that ads steering consumer behavior in this

96 One term to describe such an occurrence is a "sludge." For a discussion on how to assess interventions that make a person undertake an action she would prefer not to undertake before doing so, and regrets after doing so, see CASS Sunstein, On FreEdom (2019).

97 An interesting discussion about the concept of "vulnerability" of consumers is currently taking place in the European academia. EU consumer law used to treat vulnerability as a static quality of certain kinds of consumers (children, the elderly, people with mental health problems, etc.). But in a world where we can see ads and act on them anytime, everyone is potentially vulnerable every now and then. I might be generally knowledgeable about the market, I might even be an expert, but when I am tired and stressed at the end of the day, I might make choices irrational even by my own standards. Hence, the idea here is to reconceptualize vulnerability as dynamic state in which every consumer can sometimes find herself in. For a discussion of this problem, as well as the potential implications for the consumer protection law, see N. Helberger, et al., EU Consumer Protection 2.0: Surveillance, Consent and the Vulnerable Consumer. Regaining Citizen Agency in the Information Economy, Eur. ConsumER ORG., 12-20 (Sept. 30,2020 ) (manuscript with the author, available at https://www.beuc.eu).

98 See Matthew 0. Jackson \& Leeat Yariv, Collective Dynamic Choice: The Necessity of Time Inconsistency, 7 Am. Econ. J. Micro. 150 (2015); Geoffrey Heal, Discounting: A Review of the Basic Economics, 74 U. CHI. L. REV. 59 (2007). 
way (given, among others, the possibility of on-the-spot purchases online) is potentially illegal under Section 2 of the Sherman Act. 99 In brief, this argument holds that with easy access to online information that ensures consumers can find what they really want, the social function of ads tends to be more and more about preference and behavioral manipulation. ${ }^{100}$ In this context, note how Facebook Inc.with its ability to reach you anytime, in any moment of vulnerability, maybe even caused by the platform itself, based on all the data it has about you and millions of others - can throw at you the "fast food dinner ad" on steroids. Commercials are not only designed to be convincing in themselves (like the old radio stuff) but also tailored specifically for you. All this in the environment where you are just two clicks away from ordering and paying for the product online.

Because consumers have no choice but to accept targeted advertising on Facebook, this constitutes a higher price for users. Moreover, as suggested above, Facebook Inc. has incentives to have its users spend as much time on the platform as possible. ${ }^{101}$ Acting upon that incentive-through the design of the interface/newsfeed's algorithms - might lead consumers to spend more time on the platform than they would otherwise choose. As a result, consumers receive a lower quality service. Hence, service design increasing the engagement above the levels factually desired by the users constitutes a lower quality of the service. Finally, the unintended behavioral consequence of Facebook Inc.'s activity might be social media addiction as demonstrated by researchers. ${ }^{102}$

How would Greenbook diminish these costs? First, when it comes to ads, the gain is rather evident-there would be no ads. One unwanted purchase that you avoid every month renders the subscription cost worthwhile, even absent any other gains. Second, when it comes to time spent on the platform and the risk of addiction, there is no incentive on Greenbook Inc.'s part to have you spend as much time as possible on the

99 See Ramsi A. Woodcock, The Obsolescence of Advertising in the Information Age, 127 YALE L.J. 2270, 2308 (2018) ("Persuasive advertising excludes competitors from the market for the advertised product, by making consumers prefer the advertised product over those of competitors. This makes a monopolization claim under Section 2 of the Sherman Act, which attacks conduct that excludes competitors from markets, the appropriate vehicle for challenging advertising on antitrust grounds. To prevail on a monopolization claim under section 2, a plaintiff must show that the defendant (1) has engaged in an illegal form of exclusionary conduct and (2) enjoys monopoly power in the market from which the defendant has excluded competitors.")

100 Id. at 2299.

101 See BALKIN, supra note 14.

102 See Anindita Chakraborty, Facebook Addiction: An Emerging Problem, 11 Aм. J. PSYCHIATRY 7 (2016). 
platform. Greenbook Inc. wants you to keep paying the subscription fee. Once the money comes in, Greenbook Inc. is indifferent as to whether you spend five or sixty hours using it a month. Because Greenbook Inc. does not incur costs when you limit your engagement, it could proactively help you spend less time on the platform. For example, it could ask you how much time you wish to spend there and display a red pop-up when your daily/weekly limit is exceeded. For Facebook Inc., that is a costly feature to have. For Greenbook Inc., it might be a profitgenerating feature, as more people-generally unhappy with wasting time on social media but wishing to remain a part of the networkwould choose it over the competitors.

Will this solve the problems of addiction and wasting time? Again, not entirely. As with every addiction, there are reasons beyond the features of the product that lead people to overuse it. People might go to their facebook to numb their minds, to scroll, etc.; however, there is a difference between overusing something because we enjoy it (in the short term) and overusing it because it is made up of addictive components. ${ }^{103}$ Imagine that it is possible to produce tobacco or alcohol that does not cause physiological addiction. Would that mean that people stop using it? No, because some people like it. Would it mean that no one would overuse it? Again, no, because some people might like it so much that even absent the addiction they would still consume it in excess. But if someone wanted to stop, quitting would be so much easier. The difference between cigarettes and alcohol on the one hand and facebooks on the other is that we are not able to produce the former in a less addictive form, whereas we absolutely can with the latter. The reason is that unlike with substances like cigarettes or alcohol, the features of the facebook product are not the same ones that make it addictive-the features of the business model are. And the business model could be different.

In these two subsections, we analyzed how a different business model could disincentivize facebooks operators from using data for nefarious purposes. But the problem with Facebook Inc. is not just the abuse of data-it is also privacy and security itself. The mere availability of data about our lives stored somewhere is potentially costly. Let us see how that could be avoided.

103 For specialized references to the literature suggesting that online platforms are currently designed to addict, see Rosenquist \& Scott Morton, supra note 12, at 2 "'The stimuli produced by digital platforms are not physical substances consumed by the body such as recreational and prescribed drugs, however, their effects on the brain follow the same common pathway of reward through the nucleus accumbens, which in turn regulates pathways of addiction."). 


\section{Privacy (as Security) Costs: Opportunity Makes the Thief}

Facebook Inc. imposes "privacy as security" costs on its users by amassing unnecessary (from the technical point of view) data, capable of being stolen by hackers. This is a potential cost that users will bear if the breach occurs, potentiality being subject to uncertainty. 104

As noted at the beginning of this subsection, "privacy" tends to be treated as an "umbrella" category for all the data-related harms. Traditionally, at least within American privacy torts jurisprudence, privacy has been associated with disclosure of information about one's private life against the will of the person whom this information concerns. ${ }^{105}$ In the current socio-technological reality, there are two ways in which this type of "disclosure" by Facebook Inc. can occur: (i) intentional sharing of personally indefinable information by the company and (ii) a security breach (data leak). Leaving the discussions about the former to legal scholars interested in the nitty-gritty of the privacy law theories, I would like to focus on the latter, significant from in terms of this paper's argument.

Facebook Inc. has been involved with scandals concerning hacking and data leaks/breaches when third parties illegally obtained access to users' data. ${ }^{106}$ There are many reasons why these types of breaches are harmful to consumers, 107 including the fact that hackers, unlike Facebook Inc., are not in a business relationship with users and have no market (or other) incentives against publicly sharing this data or using it to blackmail the users. ${ }^{108}$

Hence, the fact that Facebook Inc. chooses to construct its business model around extensive data collection about the users, given the risk of hacking, lowers the quality of service provided to users, constituting a higher price that consumers will (potentially) have to pay if or when a breach materializes. Conversely, in a competitive market, where other

104 It is also a risk that users incur, given the impossibility of knowing the probability. For the distinction, see Frank Knight, Risk Uncertainty \& Profit (1921).

105 See William L. Prosser, Privacy, 48 CaL. L. Rev. 383, 389 (1960) (enumerating four types of privacy torts: "1. Intrusion upon the plaintiff's seclusion or solitude, or into his private affairs; 2. Public disclosure of embarrassing private facts about the plaintiff; 3. Publicity which places the plaintiff in a false light in the public eye; 4 . Appropriation, for the defendant's advantage, of the plaintiff's name or likeness"); Samuel D. Warren \& Louis D. Brandeis, The Right to Privacy, 4 HARV. L. Rev. 193 (1890).

106 See Mike Isaac \& Sheera Frenkel, Facebook Security Breach Exposes Accounts of 50 Million Users, N.Y. TimeS (Sept. 28, 2018), https://www.nytimes.com/2018/09/28/ technology/facebook-hack-data-breach.html.

107 See Kilovaty, supra note 10, at 1184.

108 For an argument that a legal obligation of this sort should exist between the users and the platforms, see Jack M. Balkin, Information Fiduciaries and the First Amendment, 49 U.C. DAVIS L. REV. 1183 (2016). 
facebook providers could adopt different business models, the protection of users' privacy and security could stem from their less dataheavy conduct. More competition in the facebooks market would benefit consumer privacy and data security.

Of course, Greenbook Inc. would still store some data-potentially a great amount of it. In a way, a facebook is about storing and sharing information. Nevertheless, the amount and the kind of data stored would differ. As of now, Facebook Inc. has an incentive to store not only the data you provide (photos, posts, live events, friendships, occupation, etc.) but also data about your behavior on-platform and off-platform. The amount of time you spent there, what articles you click, how you react to all the posts, what time of a day you visit what websites-all this information can be and is being monetized. For Greenbook Inc., no such incentive exists. Simply put, Greenbook would collect much fewer data about you than Facebook does, even if you were using it in exactly the same way. This lowers the potential costs that occur when a hack happens-the Cambridge Analytics scandal, by definition, would have no factual chance of occurring on Greenbook.

\section{Free Riding on Users' Intellectual Property and Labor}

Facebook Inc. harms users by free riding on their creative content, including their copyright-protected content and their labor, understood as data creation and service improvement. ${ }^{109}$ In a competitive market, users would choose to be compensated for the value they provide to the platform.

One of the reasons Facebook is such an appealing platform to spend time on is that it allows users to engage with creative content. The pictures you upload, the funny or exciting posts you write, or the comments you scribble are not only a way for you to express yourself, for others to stay in touch with you, but also for Facebook Inc. to retain its high user base that "enjoys" all this content.

As some of the content that people upload is copyright protected, Facebook Inc. needs a license to display it legally. Any future facebook provider willing to allow users to make their photos and posts available to the public will need some license from a user, assuming the content passes the threshold of copyright protection. ${ }^{110}$ Specifically, the provider will need a license to copy, display, and make the content

109 See PoSNer \& WeYL, supra note 11, at 207-09.

110 In this case, the most important test is "originality." For an overview of the ways various jurisdictions define this concept, see Elizabeth F. Judge \& Daniel Gervais, Of Silos and Constellations: Comparing Notions of Originality in Copyright Law, 27 CARdozo ARTS \& EnT. L.J. 375 (2009). 
available to other users, depending on how the platform uses the content. 111

The business conditions of this license, however, are not in any way predetermined. Specifically, the fact that the license is royalty-freeusers do not get paid, even if millions see their posts-is Facebook Inc.'s business decision, which is easy to force upon users because Facebook Inc. is a monopolist. Nevertheless, these conditions constitute a cost. In Facebook Inc.'s Terms of Service, we read:

The permissions you give us:

....

... Nothing in these Terms takes away the rights you have to your own content. You are free to share your content with anyone else, wherever you want.

However, to provide our services we need you to give us some legal permissions (known as a 'license') to use this content. This is solely for the purposes of providing and improving our Products and services as described in Section 1 above.

Specifically, when you share, post, or upload content that is covered by intellectual property rights on or in connection with our Products, you grant us a non-exclusive, transferable, sub-licensable, royalty-free, and worldwide license to host, use, distribute, modify, run, copy, publicly perform or display, translate, and create derivative works of your content (consistent with your privacy and application settings). ${ }^{112}$

As you might notice by looking at the emphasized portions of the texts, Facebook Inc.'s wording is misleading, and this contractual provision is by no means the only possible one. Facebook Inc. claims that they need a license to display your IP-created content, which is true. To do so, however, Facebook Inc. does not need a royalty-free license. It could agree to pay you a share of the profits it makes. Such sharing need not be automatic; the provider could require a minimum number of engagements with your content before paying you. But the fact that Facebook Inc. does not allow you to participate in the profits from your work at all means it is free riding off of your content.

111 See 17 U.S.C. § 106; U.S. Copyright Office, Making Available Study, CoPYRIGHT.Gov, https://www.copyright.gov/docs/making_available (last visited Apr. 8, 2021).

112 See Facebook Terms, supra note 50, at $\S 3$ (emphasis added). 
Many other platforms that make a business of giving people access to creative content (YouTube, Spotify, Netflix, etc.) do share profits with the content creators. ${ }^{113}$ The difference is such that these creators are often either represented by professional agents or have explicitly transferred their copyright to producers-read, corporations-with bargaining power sufficient to demand compensation.

Moreover, on top of the right to profit from users' creative content without remuneration, Facebook Inc. also benefits from free riding on users' labor.114 All the activities that users engage in-from tagging their friends on photos to rating businesses or translations to reacting to others' posts-are sources of data that Facebook Inc. uses to train its facial recognition, translation, and ad algorithms. This is not data that Facebook Inc. collects about users. This is data that users produce for Facebook Inc., for free.

Imagine I run a start-up company that creates various machinelearning-based tools. To train my algorithms, I need annotated data. 115 Someone must tag it (indicate what is on the picture, or how to translate a given word, or whether a news article contains a happy or sad story). Imagine I ask you to spend two hours a week: (i) marking the faces of people you know on photos I show you; (ii) correcting my translations; and (iii) marking if the things I show you make you laugh, angry, sad, or surprised. Through this labor of yours, combined with the work of millions of other people, I can create robust, reliable, and profitable instances of machine-learning-powered tools, or what is now commonly referred to as "artificial intelligence."116 You might agree to do this for me, but you will ask for money. The laborer deserves her payment. And yet, in the case of Facebook Inc., more than two billion laborers provide this work for free.

Note that Facebook Inc. neither has to collect the data from users to improve its services (it could just as well hire external contractors to provide the data) nor keep all the profits to itself. This a business decision made in an environment with no competitor offering payment or a better deal for consumers. This is a decision a monopolist made to impose costs on users and extract all the surplus. The lack of royalties for your IP-protected content, from which Facebook Inc. benefits, and

113 James H. Richardson, The Spotify Paradox: How the Creation of a Compulsory License Scheme for Streaming On-Demand Music Platforms Can Save the Music Industry, 22 UCLA ENTM'T L. Rev. 46, 57-62 (2014).

114 Jamal Robinson, How Facebook Scales Machine Learning, MEdium (Feb 3, 2019), https://medium.com/@jamal.robinson/how-facebook-scales-artificial-intelligencemachine-learning-693706ae296f; see also POSNER \& WeYL, supra note 11, at 207-09.

115 See Ethem Alpaydin, Machine Learning: The NeW AI 29-54 (2016).

116 See id. at 17-20. 
the lack of salary for the labor you provide by producing data it will use to train its algorithms are a part of the price you are currently paying for access to Facebook Inc.'s service.

Greenbook Inc.-or some other competitor-could choose to pay users a share of their profits for the value of their content and labor, as Spotify and YouTube do. Of course, this would not be a lot of money for most people. Still, there is no reason why it should stay with the monopolist.

To sum up, this Part explored exactly why using Facebook is not "free" and analyzed the types of costs it imposes on consumers, going beyond "data and attention" (cognitive, behavioral, and privacy-security harms, as well as Facebook Inc.'s free riding on users' content and labor). This Part also tried to imagine how, in a competitive market, consumers could, and would, either refuse to suffer those harms (by choosing a different provider) or require compensation. In short, I argued that interoperability in the market for facebooks is necessary to increase competition and that competition is necessary to lower the costs to consumers.

\section{TOWARD THE WORLD OF FIFTY FACEBOOKS}

In this final Part, I sketch the possible ways of getting from where we are today to the world of fifty facebooks. First, I take a closer look at the concept of interoperability as used in the existing legal discourse, survey the state of the art, and apply it to the problem of facebooks. Second, I look at the role of regulation and antitrust enforcement in facilitating the competitive market in facebooks, as well as preventing certain types of abusive behavior by providers. Third, I survey several commonplace objections to the interoperability of online platforms, including innovation, privacy and security, property, and distributive effects. Finally, I offer a brief reflection on the possibility of scaling up the idea presented in this paper to other platforms.

\section{A. Interoperability}

The reader will have noticed that I have not defined "interoperability" until now. I wanted the argument to proceed bottomup, from the single case study of Facebook Inc., and not top-down, from some abstract definition of "interoperability." In other words, I wanted us first to imagine, in several ways, what the world of fifty facebooks could look like and why it would be beneficial before getting into the details of how it could work from the technical perspective. This is because, at least from the perspective of this paper's argument, interoperability is a means to the end of higher consumer welfare, not a 
goal in itself. ${ }^{117}$ This is not to say that we should not aim for a more interoperable internet as the goal118-on the contrary, I believe we probably should; 119 it is just not the argument I tried to advance in this Article. Nevertheless, one should remember that numerous scholars have explored, and several national and transnational reports have taken up, the idea of interoperability in information technologies, including the interoperability of platforms. ${ }^{120}$ Building on this work, let us try to better define it and distinguish certain key concepts.

Put simply, products are interoperable if they can work together. This means different things depending on the context. For example, if you have an iPhone and a contract with AT\&T, and I have a Samsung phone and use T-Mobile, we can text and call one another; this means that various phones and various telephone providers are horizontally interoperable. If you can charge your headphones with the USB charger you got when buying a hair trimmer, then the charger and the device are vertically interoperable. On the contrary, Apple chargers and non-Apple devices are not interoperable. Further, you can open a PDF file in dozens of readers or access most websites with several web browsers because the files and the software are interoperable. On the contrary, if you can only listen to an audiobook you bought from Amazon using the Audible app, this means that the file is not interoperable with other programs.

117 For an argument that we should generally treat interoperability as a means to an end, not a goal valuable in itself, see Wolfgang Kerber \& Heike Schweitzer, Interoperability in the Digital Economy, 8 J. Intell. Prop. Info. TeCh. \& Electronic Com. L. 39, 58 (2017).

118 For an argument that interoperability is valuable as goal in itself, see Cory Doctorow, Interoperability: Fix the Internet, Not the Tech Companies, Elec. Frontier Found. (July 11, 2019), https://www.eff.org/deeplinks/2019/07/interoperability-fixinternet-not-tech-companies.

119 See infra Section IV.D.

120 See Opening Standards: The Global Politics of Interoperability (Laura DeNardis ed., 2011); John Palfrey \& URs Gasser, Interop: The Promise and Perils of Highly InTERCONNECTED Systems (2012); Inge Graef, Mandating Portability and Interoperability in Online Social Networks: Regulatory and Competition Law Issues in the European Union, 39 Telecomm. Pol'y 502 (2015); Chris Riley, Unpacking Interoperability in Competition, 5 J. Cyber Pol'y 94 (2020); British Competition \& Markets Auth., Online Platforms AND Digital Advertising: MARKet Study FinAl Report (2020), https://assets.publishing. service.gov.uk/media/5efc57ed3a6f4023d242ed56/Final_report_1_July_2020_.pdf (United Kingdom); JaCques Crémer, Yves-Alexandre de Montjoye \& Heike SChWeitzer, European Commission, COMPetition Policy For the Digital ERA (2019), https://cnnumerique.fr/files/uploads/2020/ra-cnnum-concurrence-web(1).pdf (European Union); L'étude de cas sur l'interopérabilité des réseaux sociaux, ConsEIL NATIONAL DU NUMÉRIQUE (July 2020), https://cnnumerique.fr/Interoperabilite Concurrence_Etude (France); THE STIGLER RePort, supra note 12, at 113-18 (United States). 
John Palfrey and Urs Gasser define interoperability, in the context of information technologies, as "the ability to transfer and render useful data and other information across systems, applications, or components." 121 They nuance the definition by distinguishing four layers of interoperability: technological, data, human, and institutional.122 The lesson to be learned from their work is that interoperability is much more than just passing a law or developing technical standards. Concrete technical issues are a legion, and a lot of possible ways of achieving the goals exist (including both private and public interventions, and both unilateral and cooperative actions). ${ }^{123}$ Moreover, interoperability is as much about imagination and willingness to change things as it is about technicalities. Or, in Palfrey and Gasser's words, “[ $\mathrm{t}]$ he problems associated with interop are just as much about culture as they are about technology."124

Applying their insights to the question of facebooks' interoperability, one will notice that, at least in theory, it could emerge based on Facebook Inc.'s unilateral decisions. Especially where vertical interoperability is concerned, there have always been many apps running on Facebook. ${ }^{125}$ From the business perspective, Facebook Inc. benefits from additional apps increasing its platform's "utility" to users. The trouble is that, as of today, Facebook Inc. retains full control over who can offer services vertically interoperable with its platform and under what conditions they may do so. Hence, it might disallow certain apps once it considers them to be too competitive (as it did with Vine) ${ }^{126}$ or generally keep certain functionalities fully to itself (like content filtering and moderation). Moreover, it has never voluntarily allowed horizontal interoperability. Here is where we need to categorize interoperability by kind based on the attitude of various concerned actors.

121 PALFREY \& GASSER, supra note 120 , at 5.

122 Id. at 6.

123 Id. at 14-15.

124 Id. at 5.

125 One example are games developed by Zynga Inc., most notably Farmville. See Demetrius Williams, The Rise and Fall of Zynga: A Cautionary Tale for Mobile Game Developers, TRANSLATE MEDIA (June 7, 2017), https://www.translatemedia.com/ translation-blog/rise-fall-zynga-cautionary-tale-game-developers.

126 Adi Robertson, Mark Zuckerberg Personally Approved Cutting Off Vine's FriendFinding Feature, VERGE (Dec. 8, 2018, 10:35 AM), https://www.theverge.com/2018/ 12/5/18127202/mark-zuckerberg-facebook-vine-friends-api-block-parliamentdocuments. 
Cory Doctorow, understanding interoperability as "the technical ability to plug one product or service into another product or service," distinguishes between indifferent, cooperative, and adversarial interoperability. 127 Indifferent interoperability occurs when one company is not concerned with the actions of the other; cooperative interoperability is when two parties actually cooperate to ensure the interoperability (for instance, developers of apps for a new operating system or cases for telephones).128 Adversarial interoperability, on the other hand, occurs when one party makes its product work with another without the permission, and often against the will, of the other product's producer. ${ }^{129}$ This is the case of Facebook Inc. Zuckerberg's giant has no wish to become interoperable with other services unless it approves of each and every cooperation. Doctorow's insight matters profoundly, as it draws our attention to the fact that interoperability, on top of being a problem of technology and culture, is a problem of interests and power. That is why, sometimes, the government needs to mandate interoperability. ${ }^{130}$ This, however, can happen in many different ways. Let us look at what those are.

\section{B. Regulation for, and of, Competition}

We should keep in mind the distinction between regulation as a means of obliging Facebook Inc. to open up to competition on the one hand and regulation as means of governing the world of fifty facebooks on the other. Whereas the former is not the only way to go (the company could be obliged to open up because of antitrust enforcement or choose to do so voluntarily), the latter will most certainly be necessary to, first, sustain the interoperability of services and, second, account for certain types of externalities.

\footnotetext{
127 See Doctorow, supra note 118.

128 Id.

129 For an overview of articles advancing the concept, see Cory Doctorow, Adversarial Interoperability, ELEC. FRONTIER Found. (Oct. 2, 2019), https://www.eff.org/deeplinks/ 2019/10/adversarial-interoperability.

130 See Bennett Cyphers \& Cory Doctorow, A Legislative Path to an Interoperable Internet, ELEC. FRONTIER FOUND. (July 28, 2020), https://www.eff.org/deeplinks/2020/ 07/legislative-path-interoperable-internet ("If Facebook and Twitter allowed anyone to fully and meaningfully interoperate with them, their size would not protect them from competition nearly as much as it does. But platforms have shown that they won't choose to do so on their own. That's where governments can step in: regulations could require that large platforms offer a baseline of interoperable interfaces that anyone, including competitors, can use. This would set a 'floor' for how interoperable very large platforms must be. It would mean that once a walled garden becomes big enough, its owner needs to open up the gates and let others in.").
} 
First, consider regulation as the means for obliging Facebook Inc. to open up and give competitors access to its service and network. The United States Congress or the European Union could pass a law requiring that facebook operators make themselves open to and interoperable with other services on this market. In fact, first steps in that direction have already been taken, with the ACCESS Act in the US 131 (currently in stalemate) and the newly proposed Digital Services Act in the EU. ${ }^{132}$ As of today, however, no such requirement exists. The precise content of such an obligation depends on the political choices made. For example, one can imagine the government requiring that Facebook Inc. adopt certain standards but allowing it to develop those standards in cooperation with the industry. This would be a mix of a publicly mandated interop, the details of which the private actors work out. Alternatively, the government could mandate not only adoption but certain standards as well.133 Moreover, one should remember that on top of mandating interoperability, the lawmakers might have to remove certain legislative instruments currently allowing platforms to block access technically, sometimes even through criminal actions, like the Computer Fraud and Abuse Act.134 Such a move is already foreseen (subject to limitations) in the DSA ${ }^{135}$ when it comes to research, and in the DMA when it comes to competitors. ${ }^{136}$

What precisely the enforcement mechanisms for these rules should be is a question beyond this paper's scope. One option is monetary fines for refusing to open up to competition via interoperability, issued by one of the existing regulatory agencies-the most obvious candidate in the United States being either the FCC or the FTC-or a new agency focusing on various new technology-related problems. ${ }^{137}$ Alternatively, one can imagine granting competitors private rights of action, a "right to

131 For a discussion of its contents and potential to facilitate interoperability, see Kadri, supra note 3, at 36-37.

132 In the European Union, interoperability is hinted at, but at this point formally required only in vertical relations. See Jan Penfrat, How the Parliament Stakes Out Its DSA Position, Eur. Digital RTs. (Oct. 21, 2020), https://edri.org/our-work/how-theparliament-stakes-out-its-dsa-position.

133 See Cyphers \& Doctorow, supra note 130.

134 See Kadri, supra note 3, at 30 (arguing that "Congress should amend the CFAA to clarify that the statute is inapplicable to publicly accessible websites").

135 See the DSA, supra note 33, art. 31.

136 See the DMA, supra note 34, art. 6.

137 For examples of voices proposing creation of new "digital" agencies, regulating (certain aspects) of the operations of tech companies, see generally Ryan Calo, Robotics and the Lessons of Cyberlaw, 103 CALI. L. Rev. 513 (2015); Andrew Tutt, An FDA for Algorithms, 69 Admin. L. REv. 83 (2017); see also Chapter IV, Section 1 of the DSA, supra note 33 , at 67-74 (proposing digital service coordinators). 
interoperability," and a possibility to sue Facebook Inc. (or anyone else) if they refuse access.

Second, once we achieve this goal of creating the world of fifty facebooks, we will need to regulate this market. On the one hand, issues like technical standards for interoperability, safety standards, transparency, and accountability rules make up essential elements of the legal landscape for sustaining the "world of fifty facebooks." We need to be sure that a user of A-Book can communicate with a user of BBook. Importantly, we must allow users that currently have accounts on Facebook to migrate to these other services with their existing content and connections. ${ }^{138}$ We also need to significantly increase the societal ability to monitor the activities of facebook providers. ${ }^{139}$ On the other hand, given the existence of externalities in the data-driven world,140 we might want to ban certain types of activities like discrimination and manipulation altogether.

Thomas Kadri insightfully points out that, with easier data flows, the risks of data abuse, including privacy risks, might increase. In his words, "If Congress facilitates data collection and interoperability in the ways I propose, it will become essential for legislators to pass a comprehensive data privacy law as well. The United States still lacks legislation to regulate privacy in many aspects of our daily lives." 141 Kadri calls for a federal privacy regulation, akin to the EU's GDPR or the

138 One of the legal tools that consumers and emerging competitors could make use of is the right to "data portability," currently granted to the residents of the European Union. See Inge Graef, Martin Husovec \& Nadezhda Purtova, Data Portability and Data Control: Lessons for an Emerging Concept in EU Law, 19 GERMAN L.J. 1359, 1361 (2018).

139 See Rory Van Loo, The Missing Regulatory State: Monitoring Businesses in an Age of Surveillance, 72 VAND. L. REv. 1563, 1563 (2019) ("An irony of the information age is that the companies responsible for the most extensive surveillance of individuals in history-large platforms such as Amazon, Facebook, and Google-have themselves remained unusually shielded from being monitored by government regulators."). A lot of provisions of the DSA foresee such mechanisms. See, e.g., the DSA, supra note 33, arts. $13,19,23,24,28,30,33$.

140 See Pałka, supra note 65, at 595 ("By allowing a company to collect and study information about myself, even if we assume I am fully aware of what they plan to do with my data, I impose a cost on (or at least make a decision about) you and other people. If I make it clear what my political views or religious convictions are, essentially everything I do online can later be used to infer knowledge about other people's religion and politics. 'Everything you say can and will be used against other people' would be a fair statement to include in the privacy policies written within the 'notice and choice' paradigm. The more things I buy on Amazon, the more refined suggestions to other customers will be. If I am convinced, or not convinced, by a political ad, I help ensure that its next reiteration will be even more successful in manipulating people's preferences and behavior. Even if I fully agree to the collection of my data, I impose costs on you and our fellow humans. I should not be allowed to do this so easily.").

141 Kadri, supra note 3, at 38. 
California Consumer Privacy Act. ${ }^{142}$ This is definitely necessary but arguably insufficient. One should remember that these instruments are aimed mostly at ensuring fairness in data processing by endowing individuals with certain rights and introducing transparency and accountability requirements. ${ }^{143}$ They do not, however, speak to the legality of particular purposes of data processing, like content or ad personalization, nor to problems like data-driven discrimination ${ }^{144}$ or manipulation. ${ }^{145}$ The emergence of competition may take care of some of these problems, but we must outlaw others across the board. How exactly to proceed is not predetermined; on the contrary, a democratic and political process should help us establish that. ${ }^{146}$

Similar to regulation, antitrust enforcement could play a dual role in creating the world of fifty facebooks. On the one hand, direct antitrust action against Facebook Inc. could be the means of obliging it to open up to the competition. This could happen under Section 2 of the Sherman Act $^{147}$ in the United States or under Article 102 of the Treaty on the Functioning of the European Union (TFEU). ${ }^{148}$ Both of these provisions forbid abuse of the dominant position on a given geographical and product market. ${ }^{149}$ Enforcement actions by the FTC or the European Commission could be the way of legally obliging Facebook Inc. to open up to the competition. The chances, given the current jurisprudence in the US and the EU, seem rather low; however, with the large wave of progressive thought urging us to rethink the antitrust right now, ${ }^{150}$ a change in practice might be on the horizon. The newly initiated FTC lawsuit against Facebook Inc. is a perfect start to requiring the company

\footnotetext{
142 See id.

143 For an overview of consumer rights and transparency requirements in the GDPR and the CCPA, see OneTrust DataGuidance \&Future of Privacy Forum, Comparing Privacy LAWS: GDPR v. CCPA (2018).

144 See, e.g., Solon Barocas \& Andrew D. Selbst, Big Data's Disparate Impact, 104 CaLI. L. REv. 671 (2016).

145 See Kilovaty, supra note 9.

146 See Viljoen, supra note 64.

147 Sherman Antitrust Act of 1890, 15 U.S.C. §§ 1-7.

148 Consolidated Version of the Treaty on the Functioning of the European Union art. 102, May 9, 2008, 2008 0.J. (C 115) 47.

149 See id.; 15 U.S.C. $§ \S 1-7$.

150 See Bill Baer, Jonathan B. BaKer, Michael Kades, Fiona Scott Morton, Nancy L. Rose, Carl Shapiro \& Tim Wu, Wash. Ctr. For Equitable Growth, Restoring Competition in the United States: A Vision for Antitrust Enforcement for the NeXt Administration and CONGRESS (Nov. 2020), https://faculty.haas.berkeley.edu/shapiro/restoring competition.pdf; Jonathan B Baker, Jonathan Sallet \& Fiona Scott Morton, Unlocking Antitrust Enforcement, 127 YALE L.J. 1916 (2017); Guggenberger, supra note 5; Khan, supra note 24; Ramsi Woodcock, The Antitrust Case for Consumer Primacy in Corporate Governance, 10 U.C. IRvine L. REv. 1395 (2020).
} 
to open up. ${ }^{151}$ Here one should remember that the lawsuit does not need to end up with a court judgment, but quite possibly will result in a settlement. The FTC, when it comes to the negotiations, should push for horizontal interoperability in the market for facebooks.

On the other hand, adequately enforced antitrust law, especially mergers and acquisitions control, will be an essential tool for guaranteeing that a new monopolist will not re-emerge. Here, the tool to bear in mind is Section 7 of the Clayton Act in the United States, which prohibits mergers and acquisitions if the outcome "substantially [] lessen[s] competition, or [] tend[s] to create a monopoly."152 The FTC lawsuit against Facebook Inc. is a tremendous step in that direction. In addition, the antitrust laws might help with fighting against the emergence of cartels and collusive behavior that Article 101 of TFEU in the EU and Section 1 of the Sherman Act in the United States prohibit. Also, these tools will be crucial to ensuring that after the emergence of the world of fifty facebooks, we will not gradually return to where we are now.

In sum, the legal intervention should focus on (i) obliging Facebook Inc. to open up to competition; (ii) sustaining interoperability and competition in the market for facebooks; and (iii) mitigating certain horizontal risks in this market, like privacy, security, manipulation, and discrimination. There is no one best way to achieve all these aims; in this Section, I wanted to sketch an overview of the available tools.

\section{Objections}

Having provided an argument for the law to mandate interoperability in the market for facebooks, I would like to begin wrapping up this Article by addressing several objections that have been raised regarding interoperability in general. I do not claim to refute them here-doing so in one short section would necessarily require turning them into straw persons, which I would strongly prefer to avoid. But for the sake of the argument, I want to signal what these objections are and hint at the pathways for addressing them. These include: (a) privacy and security risks; (b) risk of increased homogeneity and stifling of innovation; (c) proprietary claims of the large platforms; (d) distributive effects privileging the rich at the expense of the poor; and (e) lowering the reliability of regulatory oversight that platforms currently undertake.

151 See the FTC's Facebook lawsuit press release, supra note 2.

152 Clayton Antitrust Act of 1914 § 7, 15 U.S.C. § 18 (original version at ch. 323, § 7, 38 Stat. 730 (1914)). 
Let us start with privacy and security. ${ }^{153}$ One could argue that as long as Facebook Inc. keeps all the data to itself, given its expertise and available funds, the privacy risks are lower than they would be in the world of fifty facebooks. In the end, it is easier to keep one set of servers secure than fifty such sets. Moreover, closed APIs guarantee that no nefarious actors (like Cambridge Analytica) can get access to the data which they would abuse. Opening them up necessarily comes with privacy risks. This objection is a very serious one, and lawmakers should definitely keep it in mind. A couple of points should be made, however. First, as noted in the Section above, we need to pair mandated interoperability with legal requirements for security and privacy. The problem is not that Facebook Inc. is super secure but the competitors would not be; the problem is that a general consumer privacy law is way past due. Second, as I have argued already, ${ }^{154}$ part of the problem is that Facebook Inc. currently amasses much more data about consumers than necessary. In a competitive market, business models offering to collect much fewer data could emerge, thereby lowering the stakes of a potential hack.

Further, we might fear that introducing standards (either through the government or through the industry) will lead to a higher homogeneity on the market and stifle innovation. ${ }^{155}$ This objection holds water where interoperability as a general concept is concerned. In the case of facebooks, however, we are already dealing with only one product on the market. Introducing competition through mandated interoperability will lead to innovation when it comes to both functionalities and business models.

The question of innovation is closely linked with property concerns. Advocates for business freedom could argue that Facebook Inc. has created a neat product and so forcing it to open up to competition violates the company's right to do with their proprietary algorithms and platform as they see fit. There are two ways to read this objection: deontological (it is simply unfair to take revenue streams away from Facebook Inc., who invented a facebook) or consequentialist (the company invested a lot in it, and so forcing it to open up to competition will lead to lower returns and might disincentivize future innovators). The former version of the objection definitely points to a real issue; however, it is conveniently silent about the amount of value

153 For a specification of this objection, and detailed analysis and partial rebuttal, see PALFREY \& GASSER, supra note 120, at 75-88.

154 See supra Section III.B.3.

155 For a specification of this objection, and detailed analysis and partial rebuttal, see PALFREY \& GASSER, supra note 120 , at 111-27. 
that Facebook Inc. extracts from its users already-from datafication of their lives ${ }^{156}$ to free riding on their content and labor. ${ }^{157}$ Hence, the legal intervention proposed in this Article does not violate an innocent actor's rights; it limits the profitability of a business model predicated on value extraction from billions of people. The latter consequentialist version of the objection overlooks the simple fact that once the market opens up, a huge incentive to innovate emerges. Of course, one might concede that mandated interoperability in the market for facebooks will stifle innovation in new areas. The right to monopoly profit, however, (granted through patents, for example) is always limited in time, ${ }^{158}$ and Facebook Inc. has had its share already.

Another serious objection points to the distributive effects of the intervention proposed in this paper. If we imagine that a new competitor emerges and offers a facebook service for a subscription fee, richer consumers might switch, whereas poorer ones may be stuck with the toxic business model and incur even higher costs than now (as Facebook Inc. will need to, somehow, make up for the lost profit). This phenomenon might occur both domestically and internationally, where Facebook Inc. will try to squeeze out more profits in geographical markets other than the US and the EU. This objection is important, and lawmakers should keep it in mind when designing the detailed policy. It does not have to materialize, however. First, public campaigns about the harmful effects of using Facebook might convince some people that $\$ 12$ is worth the time and mental health they will save by switching. Second, the horizontal regulation might render some of the most toxic kinds of data-driven harms unlawful. Third, the choice will not have to be binary-between either a subscription fee or Facebook Inc.-as it is today. More competitors might emerge and still offer services "for free" and display ads, but without the constant data collection and "tricking" consumers into purchases.

Finally, there is the question of public policy oversight that private companies like Facebook Inc. conduct. Rory Van Loo has documented and scrutinized the extent to which this phenomenon already widely occurs, including the FTC's conscription of Facebook Inc. to police thirdparty apps offered on its platform. ${ }^{159}$ Given the number of companies

\footnotetext{
156 See CoHEN, supra note 9; ZuBOFF, supra note 9. Platforms have become both key drivers of the datafication of important resources and active legal entrepreneurs, pursuing powerful strategies for ensuring their continued access to and de facto control of the data on which they rely. CoHEN, supra note 9, at 48.

157 See supra Section III.B.

158 See Guggenberger, supra note 5, at 8.

159 See Rory Van Loo, The New Gatekeepers: Private Firms as Public Enforcers, 106 VA. L. REV. 467, 482-83 (2020).
} 
operating online, companies like Facebook Inc. have the resources to perform oversight activities; ${ }^{160}$ and having just one Facebook makes it easier to hold the private enforcer accountable. 161 Once there are fifty facebooks, the smaller ones might have trouble performing oversight, and making sure that every single one of them does not abuse its oversight powers will become much more costly and difficult. This is also a serious objection. Each facebook does not need to perform this private oversight separately, however-a vertically interoperable company could do so. One could imagine all facebooks chipping in to fund such a company for example, in a way proportionate to their market share.

In sum, there are many objections one could raise against the idea of legally mandated interoperability in the market for facebooks. But even if each of them is based on a sound concern, none of them seem to defeat the idea generally. The solution will lie in the details of the reform. Hence, lawmakers should take note of each objection but treat them as challenges to overcome rather than discouragement.

\section{Scaling Up-Toward Anti-Platform Law?}

The argument of this Article has been limited to one case study, namely Facebook Inc. An unavoidable question arises, however-why stop at Facebook? Why not open up other platforms like Google, YouTube, Amazon, Twitter, etc.? Do we need or even want to live in the world in which the vast majority of our interactions are structured through platforms?

Julie Cohen, in her treatise on informational capitalism, observes that platforms have become a core organizational unit of socioeconomic interaction and that "[e]conomically speaking, platforms represent both horizontal and vertical strategies for extracting the surplus value of user data."162 Importantly, however, there is no technical reason to structure the internet this way. It was not so at the beginning, and it does not have to be so in the future. ${ }^{163}$ Again, changing this state of affairs is a question of both imagination and political will.

Consider some examples. YouTube is a platform hosting videos, allowing you to search for, stream, and comment on them; it also moderates the content it hosts. There is no reason why, however, one

160 See id. at $510-11$.

161 On the need and tools for accountability, see id. at 516-22.

162 CoHEN, supra note 9, at 42-44.

163 See Mike Masnick, Protocols, Not Platforms: A Technological Approach to Free Speech, Knight First AmEnd. Inst. Colum. U. (Aug. 21, 2019), https://knightcolumbia.org/ content/protocols-not-platforms-a-technological-approach-to-free-speech. 
company must undertake all of these activities. We could have several services for hosting, searching, moderating, and streaming-all interoperable with one another. We could do a similar operation with Amazon. There could be many companies that allow listing offers, provide searching abilities, and mediate contracts between buyers, sellers, and couriers. Just as we enacted "antitrust" laws at the end of the nineteenth century, taming the excessive growth of the corporate form, we could now enact "anti-platform" laws aimed at combating the excesses of consolidation of the technological form.

Of course, to provide an argument for such a sweeping intervention, we need to conduct a thorough empirical and conceptual study. Given the political climate and renewed interest in questions of interoperability, I expect we will see quite some work devoted to these problems. Importantly, this work should be done both top-down (from the concept of interoperability to particular case studies) and bottomup (from the case studies to the general conclusions). This Article is just one iteration of the latter strand.

\section{CONCLUSION}

In this Article, I have argued that the "world of fifty facebooks" is technically possible, legally achievable, and normatively desirable. I have demonstrated how Facebook Inc.'s current conduct harms competition, and how its business model imposes on consumers cognitive harms, behavioral harms, and privacy-security harms while free riding on their labor and creative content. I have shown how a facebook has become a new type of universal mode of communication and how the business model Facebook Inc. employs could be different, as it is completely contingent upon the company's business decisions, not related to the underlying technology. The "price" we pay could be lower, and quality of service higher, if only Facebook Inc. was obliged to open up its platform and its network to other competitors. The law should oblige it to do that.

As the debates about regulation of big tech-including social media and Facebook Inc.-continue on both sides of the Atlantic, we should remember that, as a society, we face a choice. We might either accept the central role that platforms like Facebook play in our socioeconomic lives and focus solely on taming the most abusive behaviors they engage in, or we might realize that there is nothing natural or necessary about this position and concentrate on restructuring the online power relationships. Doing so requires imagination and political will. This Article aims at fostering both. 